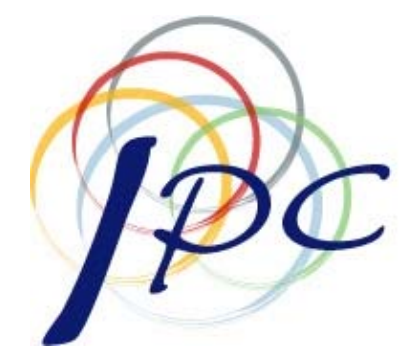

InTERnational Policy Center

Gerald R. Ford School of Public Policy University of Michigan

IPC Working Paper Series Number 66

Do Employment Subsidies Work? Evidence from Regionally targeted Subsidies in Turkey?

Gordon Betcherman

N. Meltem Daysal

Carmen Pages

May, 2008 


\title{
Do Employment Subsidies Work? Evidence from Regionally Targeted Subsidies in Turkey*
}

\author{
Gordon Betcherman ${ }^{\dagger}$ \\ N. Meltem Daysal ${ }^{\ddagger}$ \\ World Bank \\ University of Maryland \\ Carmen Pagés ${ }^{\S}$ \\ Inter-American Development Bank
}

First Version: April 2007

This Version: May 2008

\footnotetext{
${ }^{*}$ We are grateful for comments provided by Jagadeesh Sivadasan, Jeff Smith, Lucia Madrigal, and seminar participants at the University of Michigan, the Population Association of America, the IZA/World Bank Conference on Employment and Development, the Society of Labor Economists, and the World Bank. We thank Zafer Mustafaoğlu for his valuable help in coordinating with the Government of Turkey and obtaining needed data and documentation and the Turkish Social Security Administration for making available the data and for attending our queries while performing this study. A major part of this research was conducted while Carmen Pagés was at the World Bank. We bear sole responsibility for the contents of this paper, which is not meant to reflect the views of any of the individuals or institutions mentioned above.

${ }^{\dagger}$ Contact Information: The World Bank, 1818 H Street, N.W. Washington, D.C. 20433. Email: gbetcherman@worldbank.org.

$\ddagger$ Contact Information: 3105 Tydings Hall, Department of Economics, University of Maryland, College Park, MD 20742. Email: daysal@econ.umd.edu.

${ }^{\S}$ Contact Information: Inter-American Development Bank, Research Department, 1300 New York Avenue, N.W. Washington, D.C. 20577. Email: carmenpag@iadb.org.
} 


\begin{abstract}
This paper studies the effects on registered employment, earnings, and number of registered establishments of two employment subsidy schemes in Turkey. We implement a difference-in-differences methodology to construct appropriate counterfactuals for the covered provinces. Our findings suggest that both subsidy programs did lead to significant net increases in registered jobs in eligible provinces $(5 \%-13 \%$ for the first program and 11\%-15\% for the second). However, the cost of the actual job creation was high because of substantial deadweight losses, particularly for the first program (47\% and $78 \%$ ). Because of better design features, the second subsidy program had lower, though still significant, deadweight losses (23\%-44\%). Although constrained by data availability, the evidence suggests that the dominant effect of subsidies was to increase social security registration of firms and workers rather than boosting total employment and economic activity. This supports the hypothesis that in countries with weak enforcement institutions, high labor taxes on low-wage workers may lead to substantial incentives for firms and workers to operate informally.

Keywords: Employment subsidies, deadweight loss, formalization, social security contributions.

JEL Classifications: H32, J23, J32.
\end{abstract}




\section{Introduction}

Persistently high unemployment rates have led many countries in Europe and elsewhere to implement employment subsidies with the objective of encouraging employment creation. On average, such programs amount to about one-quarter of total expenditures on active labor market policies in OECD member countries (OECD, 2003). While policymakers tend to equate the number of beneficiaries to the net employment effect of such programs, estimating the actual impact is not so straightforward. Many beneficiaries may have found jobs independently of the subsidies. In addition, subsidies may cause some workers to lose their jobs, either due to changes in relative wages (substitution effects) or because subsidies reduce the market share of some firms relative to others (displacement effects). For all these reasons, the net employment effects of the subsidies may be far from the administrative number of beneficiaries. Estimating the true impact of such initiatives requires building counterfactuals of what would have been the employment outcome in the absence of the subsidies, a difficult task given the lack of random assignment programs. Despite the high interest in such measures, there are very few studies which rigorously measure the impact of wage subsidies. This is particularly the case for general tax cuts given the difficulties involved in finding appropriate control groups.

In this paper we examine the effects on registered employment, earnings and number of registered workers of two regionally targeted employment subsidies offered by the Government of Turkey to encourage investment and employment in low-income provinces. This paper makes a number of contributions to the literature. First, it makes use of the progressive coverage expansion of the programs to identify appropriate treatment and control groups to estimate their effects. The research examines the incentives given by Law 5084 (2004), which covered 37 provinces and those given by Law 5350 (2005), which expanded coverage to 13 additional provinces, and modified qualification rules and subsidy amounts relative to the first scheme. Both laws subsidized employers' social security contributions, employee personal income taxes, energy consumption and land. Since these programs affected some provinces but not others, we estimate their effects by means of a difference-in-differences methodology and explore the robustness of the results to a number of different specifications of models and control groups. In particular, in addition to considering as natural control groups, the groups of provinces which are not exposed to treatment, we construct alternative controls by selecting provinces which present similar pre-treatment trends. This regional ap- 
proach has been used to study the effects of other labor market policies and institutions in the U.S. and elsewhere. ${ }^{1}$

Second, this paper examines the effects of program design by focusing on the differential effects of two subsidy programs of similar nature but with different eligibility conditions and subsidy amounts.

Third, the paper examines the effects of these programs on a number of outcomes normally not considered in the literature. In addition to effect on wages, the paper distinguishes between employment effects at the intensive and extensive margin. This distinction is important, not only to assess the effects on firm creation and number of jobs per firm, but also because one way in which firms can circumvent eligibility conditions for marginal programs is by shifting existing workers to newly created firms. The paper also examines whether employment effects are due to the creation of new jobs or the conversion of unregistered employment to registered jobs.

The Turkish economy comprises an appropriate setting to study this question because of its high level of taxation on labor. ${ }^{2}$ In Turkey, combined employer-employee contributions to finance pensions and disability insurance, health insurance, unemployment benefits, and workers' compensation constitute $36.5-42 \%$ of gross wages. ${ }^{3}$ Income tax ranges from $15-35 \%$ of the gross wage. ${ }^{4}$ Comparisons of the tax wedge on labor income in Turkey with the EU-15 countries (pre-2005 members) and a selection of (new accession) EU-10 countries for workers at different earnings levels and with different family characteristics indicates that for families and singles with children, Turkey's taxes on labor are among the highest in the OECD. ${ }^{5}$ This is especially the case for low-wage workers with children where Turkey has the highest tax wedge of all of the OECD countries (World Bank, 2006). Other important features of the Turkish economy are low job creation, low employment and participation rates and a high

\footnotetext{
${ }^{1}$ See for example Autor et al. (2006, 2007) or Besley and Burgess (2004).

${ }^{2}$ Throughout the paper, "labor taxes" is used as a term to include both social security contributions (levied on employers and employees) as well as personal income taxes levied on employees.

${ }^{3}$ The range is due to contribution rates for work injury which vary by industry.

${ }^{4}$ Between 2000 and 2004, income tax rates ranged from $15-40 \%$. In 2005 , the top rate was cut to $35 \%$ and the number of brackets was reduced from six to five.

${ }^{5}$ The "tax wedge" is defined as income taxes and combined (employer-employee) social security contributions, minus cash benefits, as a percentage of total labor compensation. The calculations of the tax wedge are based on OECD estimates with additional calculations made by the World Bank to take into account Turkey's consumption tax credits which were not included by the OECD. Note that payroll taxes account for about $70 \%$ of Turkey's overall labor taxes.
} 
share of workers in the informal economy (one in three workers in urban areas and three in four in rural areas are not registered with social security).

Our findings suggest that both subsidy programs did lead to significant net increases in registered jobs in eligible provinces. Depending on the model specification, estimated registered employment gains range from 5\%-13\% for the subsidy scheme under Law 5084 and from 11\%-15\% for Law 5350. However, the cost of the actual job creation was high, because of substantial deadweight losses. This was particularly true for the first program where we estimate that between $47 \%$ and $78 \%$ of the subsidized jobs would have been created without the program. Because of better design features, the program under Law 5350 had lower, though still significant, deadweight losses (23-44\%) and, as a result, this appears to have been more cost-effective even though the subsidies themselves were higher than under Law 5084. Although data limitations constrain our capacity to test whether the dominant effect of the subsidies was to increase social security registration of firms and workers or to boost total employment and economic activity, the evidence we have suggests the former was more important. This supports the hypothesis that in countries with weak enforcement institutions, high labor taxes on low-wage workers may lead to substantial incentives for firms and workers to operate informally.

The rest of the paper is organized as follows. Section 2 provides a brief review of the existing literature, while section 3 describes the regional incentives. Section 4 presents the data, our identification strategy, and the descriptive statistics. Main results are provided in sections 5 and 6 , and a simple cost-benefit analysis is conducted in section 7 . Finally, section 8 concludes.

\section{Previous Literature}

Employment subsidies aim to reduce the cost of labor to employers. ${ }^{6}$ They can be applied to all employment or only to new hires (marginal subsidies). They can also be general, in the sense of applying to all workers and establishments, or specific, if only certain types of workers (for example, low-wage, youth, long-term unemployed, women, or disabled workers) or certain sectors or geographic locations qualify. Subsidies can be implemented as direct

\footnotetext{
${ }^{6}$ We use the terms "employment subsidies" and "wage subsidies" interchangeably to refer to subsidies that reduce the cost of labor for employers.
} 
wage refunds or, quite commonly, as credits on social security contributions and other labor taxes.

To determine the effects of employment subsidies, economists have resorted to two approaches. The first is to make inferences based on estimates of the elasticity of labor demand. The second is to directly estimate the employment effects of actual subsidy measures.

Regarding the first approach, labor demand elasticity estimates give a measure of the expected percentage change in employment given a percentage change in labor costs. However, this approach is confounded by the fact that, a priori, it is unclear whether the incidence of the subsidy falls on the employer or on the employee, which depends on the elasticity of the labor demand and labor supply. When the incidence is fully on the employer, subsidies will lead to lower total labor costs and increased labor demand. However, when the incidence is on the employee, the result will be higher take-home pay for workers and no effect on labor demand. In the intermediate case when the two parties share the burden of a tax, and assuming competitive labor markets, both employment and wages will increase. Other factors can also come into play. One is whether minimum wages are binding. In that case, excess supply of labor implies that firms can recruit more workers without having to increase wages.

The existing literature provides some guidance on the plausible range of labor demand elasticity estimates with most estimates clustering around the -0.30 to -0.50 range (Hamermesh, 1993). Yet, as noted above, labor demand elasticities do not fully capture the employment effects of changes in subsidies (or labor taxes) because that depends also on the extent to which they are shifted on to employees (also commonly referred as "pass through"). Studies provide a wide range of estimates, which indicate that, in some cases, the pass through can be quite large. For example, research in Latin America suggests that anywhere from $20-70 \%$ of the employer's social security contributions are passed on to the worker (Heckman and Pagés, 2004). However, at least one study for Chile finds full wage shift and no employment effects (Gruber, 1997). For OECD countries, Nickell (2003) concludes that the most reasonable assessment based on the literature available is that labor taxes have a modest effect on employment and therefore tax credits should also exert small effects. He concludes that a 10-percentage point change in the tax wedge can be expected to affect employment by between 1-3\%, "... a relatively small but by no means insignificant effect" (p. 8). It should be noted however that this conclusion refers to across-the-board tax credits. The evidence 
suggests that the rate of pass-through declines around the minimum wage (Taymaz, 2006). Therefore, tax credits might have larger effects for low-wage workers.

An arguably better approach to measuring the effects of employment subsidies is to evaluate the results of specific schemes. Most studies examine the effect of programs targeted to the unemployed or disadvantaged workers and in many cases, estimates of effects are based on surveys to employers. Among the few econometric studies, Katz (1998) evaluates the Targeted Jobs Tax Credit (TJTC) in the U.S., a program that offered wage subsidies of 50\% of the first year, and $25 \%$ of the second year wages up to $\$ 6,000$, to employers of vulnerable and disadvantaged workers (economically disadvantaged youth, veterans, workers on public assistance, and disabled workers) and finds a net employment effect of $7.7 \%$. Gerfin et al. (2005) examine the effectiveness of two different temporary employment subsidy schemes to get the unemployed back to work. They find such programs to be effective for longterm unemployed, although not for workers with short unemployment spells. On their part, Galasso et al. (2001) evaluate a random assignment wage subsidy scheme targeted to workers in temporary employment in Argentina (Proempleo), which subsidized 50 percent of the first 18 months of wages for workers employed in permanent, regular jobs and find that the program provided assistance to low-wage workers in finding regular wage employment, although effects were only statistically significant among women and youth.

On the other hand, Girma et al. (2007) examine the effects of government grants to firms in Ireland, comparing employment in treated and untreated firms. They also find positive effects on employment, particularly for domestic-owned firms.

Even fewer studies examine the effect of general measures such as cuts on employers social security taxes. Among those, Bishop (1981) employs time series methodologies to evaluate the employment effect of the New Jobs Tax Credit (NJTC), a U.S. countercyclical program that awarded a $50 \%$ tax credit to the first $\$ 4,200$ of wages per worker, provided that a firm increased employment by more than $2 \%$ relative to the previous year. Bishop estimates an economy-wide employment effect of the NJTC of $0.2-0.8 \%$. A similar approach is used to estimate the effects of SPAK, a scheme introduced in 1996 in the Netherlands to permanently reduce taxes and social security contributions paid by employers for workers with wages around the minimum wage. All workers could benefit from this subsidy including those already at work. Mühlau and Salverda (2000) found that the introduction of this measure did not raise employment growth, not even in sectors, such as retail, that are intensive in 
the use of low-wage labor.

An important issue with this literature is that finding convincing conterfactuals of what would be the employment outcome in the absence of the program has proven to be difficult. Treated and not treated workers or firms may not be comparable. Matching on observables, a usual method to construct counterfactuals of treated individuals or firms, does not necessarily solve the selection issue. Finding convincing instruments is also difficult, as variables that predict participation tend to be correlated with program outcomes. Finding a counterfactual is particularly difficult when evaluating general tax cuts given the lack of suitable control groups.

Given the amount of resources devoted to these programs, and their popularity across developed and developing countries, finding appropriate ways to build counterfactuals and gathering better knowledge on their effects on a number of outcomes could greatly improve policy design. Another key issue for policy design and about which little is known is the deadweight loss of subsidies. Most estimates are obtained from interviews with employers rather than from quantitative estimates. Even though employers may not have the right incentives to report the actual numbers they would have employed in the absence of subsidies, such estimates still suggest large deadweight losses. These are associated with the impossibility of targeting subsidies to workers who would not have been hired without the subsidy. Estimates of deadweight loss range from around 53-70\% for marginal subsidization under targeted programs and up to $93 \%$ for non-targeted, non-marginal general measures (Marx, 2005).

In the next sections we attempt to fill some of these gaps by estimating the employment, wage, and firm-creation effects, as well as the deadweight losses, of two marginal subsidization

schemes targeted to low-wage workers in low-income provinces in Turkey. We believe the sequential, geographically targeted roll out of the programs provides ideal characteristics to estimate their impact.

\section{$3 \quad$ Regional Subsidies in Turkey}

We analyze the effects of a series of regional incentive schemes legislated through Law 4325 (1998), Law 5084 (2004), and Law 5350 (2005), aimed at increasing investments and employment opportunities in low-income provinces. Initially, 22 provinces were covered under Law 
4325. Law 5084 expanded coverage to an additional 15 provinces, while Law 5350 further increased coverage to 13 additional provinces. Given that our data do not cover the period before Law 4325 was enacted, we focus our attention on the subsidies offered under Laws 5084 and 5350. While such laws differed in terms of actual requirements and subsidy amounts, they included four subsidy components: (i) reductions in employers' social security contributions; (ii) credits on income taxes on wages; (iii) subsidies on electricity consumption; and (iv) land subsidies. Firms in an eligible province could receive subsidies provided they had monthly social security premium documents, electricity consumption records, and documentation showing income and corporation tax liabilities. No additional written application was required, which implied low transaction costs.

Law 5084 became effective in January 2004 and the duration of the scheme was set to be five years. It covered all provinces with per capita GDP of $\$ 1,500$ or less (in 2001) and provinces designated as priority development regions. All provinces (but one) covered under Law 4325 qualified for this program, ${ }^{7}$ and any firm that received subsidies under Law 4325 could choose to continue to receive subsidies under the first law even after the enactment of the second. In addition, 15 additional provinces not covered under Law 4325 qualified for benefits under Law 5084.

Under Law 5084, firms could obtain: (i) a subsidy on the social security contributions due at the minimum contribution base $^{8}$ and (ii) an income tax subsidy for the amount due at the minimum wage. Only new registered employment was subsidized. For establishments created on and after October 2003, subsidies were calculated based on all registered employees while for establishments that started operations before that date, subsidies were calculated based on the number of workers over and above those registered with social security on the reference date (August 2003). Establishments located within industrial zones were fully subsidized for their calculated social security contributions and income taxes, whereas establishments outside industrial zones received compensation for only $80 \%$ of such amounts.

In addition, newly created firms employing at least 10 registered workers could also

\footnotetext{
${ }^{7}$ Tunceli was covered under Law 4325 and Law 5350, but was not covered under Law 5084.

${ }^{8}$ Before July 2004 the minimum contribution base was above the minimum wage. During this period, employers who hired workers at a wage below the contribution base were required to pay, in addition to the regular employer contribution, the employee contribution for the difference between the minimum base and the minimum wage. As of July 2004, the minimum wage was raised to match the minimum contribution base. Changes in the minimum contribution base relative to the minimum wage lead to substantial changes in the cost of hiring low-wage workers, which in turn affected the demand for labor (Papps, 2007).
} 
claim an energy subsidy equal to $20 \%$ of their energy costs, plus $0.5 \%$ of that amount for each additional new worker. Existing firms, on the other hand, could get the subsidy if their registered employment increased by at least $20 \%$ since the reference date and their current employment was at least 10 workers. The subsidy was capped at $40 \%$ or $50 \%$ (in industrial zones) of total energy costs. Finally, free land was also available in some cases for firms that would employ no less than 10 workers for at least 5 years.

Law 5350 came into effect in May 2005 and modified a number of provisions in Law 5084. It extended coverage to 13 additional provinces with low socio-economic development according to an index elaborated by the Turkish State Planning Organization (SPO). Again, any firm that received subsidies under the previous law (5084) could choose to continue to receive subsidies under that law even after the enactment of Law 5350. To qualify under the new law, newly-created firms were now required to have at least 30 registered employees, while existing firms had to increase employment by at least $20 \%$ from the new reference date (January 2005), and have at least 30 employees. For existing establishments, the number of workers for which firms could claim either tax or social security subsidies could not exceed the total number of initially employed workers (at the new reference date). Law 5350 also imposed a minimum threshold size of 30 employees for new and incumbent firms to claim energy subsidies. In addition, the latter had to demonstrate an employment increase of at least $20 \%$ in order to file for benefits. However, Law 5350 increased the amount of the subsidy for each eligible worker from one time the tax and social security payable at the minimum wage (or base) to 3 times that amount. ${ }^{9}$ This implied that, for every eligible worker, the law subsidized the taxes and social security contributions of two already-employed workers. As in Law 5084, establishments located within industrial zones were fully subsidized for their calculated social security contributions and income taxes, whereas establishments outside industrial zones received compensation for $80 \%$ of such amounts.

Given the complexities of the legal framework it may be useful to provide a couple of examples (a general comparison of the laws is also provided in table 1). Consider, for example, a firm with 10 registered employees that increases registered employment by $20 \%$ from the reference date. Under Law 5084, this firm would obtain a subsidy for 2 workers

\footnotetext{
${ }^{9}$ Two additional constraints are that (i) the total value of the tax subsidy cannot exceed the amount calculated multiplying the income tax payable at the minimum wage on the number of workers and (ii) the social security subsidy cannot exceed the value that results from multiplying the social security contribution payable at the minimum base by the number of workers.
} 
during all periods in which employment was above employment at the reference date. Under Law 5350, this firm could not obtain any subsidy since 12 employees is below the minimum threshold of 30. Law 5350 favors larger firms, relative to Law 5084.

Let us now assume the case of a firm that starts with 10 registered employees and increases its employment to 30. In this case, under Law 5084 the firm would obtain a subsidy for 20 employees. Under Law 5350, the calculation is more complicated. Although the incremental employment is 20, the number of subsidized workers cannot exceed initial employment (i.e., 10). Since the total subsidy under Law 5350 is three times the incremental employment, but only 10 new workers can be counted, the total subsidy is for 30 workers. Therefore, while fewer workers would be eligible, the total amount paid in subsidies increases in Law 5350 relative to Law 5084 under this example.

One problem with marginal subsidization is that it creates incentives for firms to manipulate employment. Thus, when subsidies are given only to new hires, firms have incentives to outsource labor to other firms which, in turn, can claim that employment as marginal. ${ }^{10}$ Laws 5084 and 5350 explicitly prohibit such tactics, however enforcement is always problematic. Law 5350 may reduce these incentives since imposing a minimum of 30 employees reduces the incentives to outsource existing labor in small independent units in charge of activities such as cleaning, cafeterias, cashiers, etc., although such incentives may still exist for large firms. Figure 1 shows that if labor demand is above $L_{\min }=30$ and $L_{\max }>L_{2}$, where $L_{\max }$ is equal to twice the initial employment $\left(2 L_{0}\right)$, employment increases by much more (from $L_{0}$ to $L_{2}$ ) under Law 5350 than under 5084 (from $L_{0}$ to $L_{1}$ ).

Given the discussion in this section and the section above, it is predicted that if: (i) the subsidy schemes had a sufficient take-up rate; (ii) the demand for labor in Turkey is sufficiently elastic (i.e., it is downward sloping); and (iii) subsidies were not fully transferred to workers in the form of higher wages, then employment and gross wages would increase in a magnitude given by the elasticity of the labor demand and supply. In addition, it is also expected that Law 5350 would yield larger employment effects concentrated in the intensive, rather than the extensive, margin (i.e., primarily through expansion of existing firms rather than creation of new ones). In the next sections we describe our data and empirical methodology and assess whether our results confirm these priors.

\footnotetext{
${ }^{10}$ Marginal incentives can also motivate firms to lower the reference employment in order to be able to claim higher marginal subsidies. Under the two laws discussed, such incentives were limited by setting the reference employment sufficiently far prior to the enactment of the laws.
} 


\section{Data and Specification}

\subsection{Data}

The data used in this study come from three sources. The main source, provided by the Social Security Administration of Turkey (henceforth SSK), is a monthly panel of provincelevel data. ${ }^{11}$ It includes information on the number of registered workplaces, registered employees, total taxable earnings that are subject to contributions, and SSK premiums. We compute real average taxable earnings, dividing the total taxable earnings by the number of registered employees and correcting for inflation ${ }^{12}$. While the data are available for the period January 1998 to December 2005, we restrict our analysis to 3,555 monthly observations on 79 provinces covering the period April 2002 to December 2005. This choice was motivated by a number of data problems and inconsistencies in the earlier part of the sample. ${ }^{13}$

Data on the cost of energy subsidies, available for the period January 2004 to December 2005, was provided by the Turkish Treasury and it gives information on the number of subsidized workplaces, subsidized employment, and the cost of the energy incentives per month and province.

Finally, since data on provincial GDP is not available for the period of study, we use information on electricity consumption per province and year for period 2003-2005 in order to approximate the real level of economic activity in a province at a given point in time. This is done to assess whether employment increases in subsidized provinces are likely to be new jobs or the conversion of unregistered employment to registered jobs. This annual data set, available for 1995 to 2004, is provided by the Turkish Statistical Institute and includes information on the total electricity consumption of each province.

Table 2 provides the summary statistics for the main variables used in this study. In this table, the unit is an individual province in an individual month.

\footnotetext{
${ }^{11}$ The SSK data are actually provided on a sub-provincial basis (i.e., SSK reporting unit). The subprovincial data were aggregated up to a provincial basis for each month.

${ }^{12}$ In the rest of the paper we use "real average taxable earnings" and "real wages" interchangeably. It should be kept in mind that whenever we say real wages, we actually refer to real average taxable earnings.

${ }^{13}$ Two provinces (Kocaeli and Mus) were excluded because of unreliable data due to inconsistent administrative reporting.
} 


\subsection{Methodology}

We use a "difference-in-differences" approach to estimate the effects of the subsidies under Laws 5084 and 5350. To do so, we compare the change in performance between the period pre- and post-introduction of subsidies in the provinces that benefit from them ("treated provinces") with the change in performance in the provinces that are not covered ("control provinces"). Since the data span different subsidy regimes, covering different sets of provinces, we choose different "control" and "treatment" groups, depending on the regime being analyzed.

To clarify our characterization of control and treatment groups, we define the following groups of provinces: $D \_4325$, which contains the 22 provinces that were subsidized under Law 4325; D_5084, which includes the 15 provinces that were subsidized under Law 5084 but not covered by Law 4325; and, finally, $D \_5350$, which contains the 13 provinces that were subsidized by Law 5350 but not covered by Law 5084 . In that way, each group only includes the eligible provinces added under each consecutive law. We also define the group D_never, which contains the provinces that were not subsidized under any law. The list of provinces covered under each law is graphically depicted in Figure 2. Similarly, it is also useful to define three separate time periods: Period_0, which covers the period before January 2004; Period_1 which covers the period between January 2004 to April 2005, when Law 5084 was in effect, and when both $D \_4325$ and D_5084 provinces received subsidies under Law 5084; and Period_2, which covers the period between May 2005 to December 2005 in which provinces D_4325, D_5084 and D_5350 were eligible to receive subsidies under Law 5350 .

There are two "natural" control groups that can be used to estimate the effect of Law 5084 on $D \_5084$ provinces. The first one is given by $D \_5350$. These are provinces that are very similar in terms of income, geographical location, and density of population to the provinces in the $D \_5084$ group but fell above the minimum income per capita threshold to qualify for subsidies under Law 5084 (see Table 3 and Figure 2). The second natural control group is the D_never provinces, which did not receive subsidies under any subsidy scheme. Both have their advantages and disadvantages. On the one hand, $D \_5350$ provinces are similar in terms of income and other characteristics to provinces $D \_5084$ and therefore may offer a better counterfactual of the evolution in a number of economic variables had the subsidies not taken place. On the other hand, it may be argued that economic incentives may create stronger substitution effects between similar and geographically close provinces 
than between provinces that differ substantially in income and other attributes. From that point of view, the D_never group may give a better idea of the effects of the subsidies net of substitution effects.

Similarly, D_never provinces constitute a natural control group when estimating the effect of Law 5350 on $D \_5350$ provinces. The fact that we can only observe the first 8 months of subsidies under Law 5350 means that our results for that scheme are based on less evidence than is the case for Law 5084 .

Using provinces that do not receive the treatment as a control group for those that receive the treatment is intuitive and quite common in practice. However, a major pitfall of such a strategy is that the identifying assumption of difference-in-differences models (that the comparison group provides the counterfactual of what would have happened in the treated group) is not guaranteed to hold since control and treated provinces can have different pre-treatment evolutions in outcomes. In order to overcome this problem, we construct "alternative" control groups for D_5084 and D_5350 provinces. These alternative control groups consist of untreated provinces that had the same pre-treatment trend in outcomes as treated provinces. ${ }^{14}$ To find these provinces we estimate the following specifications:

$$
\begin{gathered}
Y_{j t}=\sigma_{0}+\text { Month } \beta_{0}+Y \text { ear } \beta_{1}+D \_5084 * \text { Month } \beta_{2}+D \_5084 * \text { Year } \beta_{3}+v_{j t} \\
Y_{j t}=\sigma_{1}+\text { Month } \theta_{0}+Y \text { ear } \theta_{1}+D \_5350 * \text { Month } \theta_{2}+D \_5350 * Y e a r \theta_{3}+\eta_{j t}
\end{gathered}
$$

where $Y_{j t}$ is employment or number of establishments (in log levels or in growth rates), Month is a vector of month dummies, Year is a vector of year dummies and $v_{j t}$ and $\eta_{j t}$ are error terms. Each of these specifications analyze the differential evolution of the outcomes during the pre-treatment period in the treated provinces relative to the control group. In particular, specification 1 is used to choose an alternative control group for D_5084 provinces and is estimated with data from D_5084 provinces and a candidate control province for the pre-treatment period 0 . The pool of candidate control provinces is given by the 31 D_never provinces and the 13 D_5350 provinces. We choose as alternative control provinces those for which an F-test that the interaction terms are jointly zero cannot be rejected for at least 3 of the 4 outcomes (employment and establishments, growth and levels) Of the 44 candidate

\footnotetext{
${ }^{14}$ For details on this strategy, see Evans and Lien (2005).
} 
provinces, 10 passed this test (6 D_never and 4 D_5350 provinces). ${ }^{15}$ We label these as the "Alt_5084" control group.

Similarly, specification 2 is estimated with data from $D \_5350$ provinces and a potential control province for period 1. In this case, the alternative control group is chosen from the 31 D_never provinces. An analogous F-test yields an alternative control group with 11 provinces. ${ }^{16}$ We name these as the "Alt_5350" control group.

Given the description of our different treated and control groups, we next move on to estimating the effects of the laws on subsidized provinces. In order to do so, we use the following two specifications:

$$
\begin{gathered}
Y_{j t}=\alpha_{0}+\delta_{0} \text { Period_l } 1+\delta_{1} D \_5084+\delta_{2} D \_5084 * \text { Period_ } \_1+\epsilon_{j t} \\
Y_{j t}=\alpha_{1}+\gamma_{0} \text { Period_2 }+\gamma_{1} D \_5350+\gamma_{2} D \_5350 * \text { Period } \_2+\nu_{j t}
\end{gathered}
$$

where $Y_{j t}$ is an outcome variable (employment, real wages, number of establishments) either in $\log$ levels or in growth rates and $\epsilon_{j t}$ and $\nu_{j t}$ are error terms. Specification 3 studies the effect of Law 5084 on $D \_5084$ provinces. In order to estimate this effect, we only include observations pertaining to periods 0 and 1 , and $D \_5084$ provinces and one of their control groups (D_never, D_5350 and Alt_5084 provinces). The coefficient on D_5084 * Period_1 measures whether there is a differential change in performance between period 0 and period 1 in the treatment group relative to the corresponding control group.

Similarly, specification 4 addresses the effect of Law 5350 on $D \_5350$ provinces. In this case, we estimate the model using only periods 1 and 2, and $D \_5350$ provinces and one of their control groups (D_never and Alt_5350 provinces). The coefficient on D_5350*Period_2 measures the differential change in performance between period 1 and period 2 in $D \_5350$ provinces compared to the relevant control provinces.

We enrich these basic specifications in different ways. In most specifications, we control for province-specific effects to account, among other things, for differences in population as well as differences in the level and sector distribution of economic activity by adding a set of province dummies to our basic specification. Obviously, since these variables are

\footnotetext{
${ }^{15}$ These provinces include Bilecik, Bolu, Burdur, Elazig, Isparta, Kastamonu, Nigde, Rize, Kirikkale and Yalova.

${ }^{16}$ Alternative control provinces for D_5350 provinces include Bilecik, Bolu, Burdur, Canakkale, Edirne, Isparta, Kirklareli, Zonguldak, Kirikkale, Yalova and Karabuk.
} 
collinear with the province group indicators, the latter are dropped from the specification. In some specifications we allow the time effects to differ month by month, by including a full set of dummies for each time observation in our sample. In addition, we also account for differences in the evolution of variables at the province level by including a full set of province specific-trends in some of the specifications.

Finally, following Bertrand et al. (2004), we allow for the error term to be auto-correlated within provinces by estimating Huber-White robust standard errors clustered at the province level in all specifications.

\subsection{Summary statistics}

Tables 4 to 6 provide summary statistics for monthly growth rates of registered employment, registered workplaces, and real wages. The row all provinces reports results for the 79 provinces included in this study. We also present descriptive statistics separately for provinces D_5084, D_5350,D_never, Alt_5084 and Alt_5350, and for sub-periods determined according to the enactment date of each law.

These tables provide some preliminary, descriptive evidence on the effects of these subsidy schemes on the growth rates of the outcome variables. D_5084 and D_5350 provinces experience marked increases in their average monthly growth rates of employment and workplaces during the periods when they are first covered by a subsidy scheme. In particular, the mean monthly employment growth of D_5084 provinces increases five-fold from $0.4 \%$ in Period_0 to 2\% in Period_1. Similarly, average monthly growth in the number of registered establishments in D_5084 provinces increases almost two-fold from 0.7\% in Period_0 to 1.3\% in Period_1. Employment and establishment growth in D_5350 provinces between periods 1 and 2 also experience substantial increases, reaching $2.6 \%$ (from $1.0 \%$ ) and $1.5 \%$ (from $0.5 \%$ ), respectively. On the other hand, employment and establishment growth in the D_never and Alt_5350 provinces increases at a much slower pace than in the treated provinces. Although, Alt_5084 provinces seem to experience employment growth increases in Period_1 similar to those in D_5084 provinces, they do not have increases in their establishment growth rates.

Table 6 presents summary statistics for real wage (defined as real average taxable earnings) growth across province groups and sub-periods. Unlike the employment and establishment trends, significant impacts of the subsidy programs are not apparent. There is little evidence that the effects of reduced taxes on employees are passed on to workers in the form 
of higher wages. In fact, wage growth in the treated provinces declines after the introduction of subsidies. For example, the monthly wage growth in $D \_5084$ provinces declines from $0.8 \%$ in Period_0 to no growth in Period_1. A similar pattern characterizes D_5350 provinces in Period_2, with a slight decline in average monthly wage growth from $0.3 \%$ to $-0.1 \%$. In comparison, wage growth is higher in the never treated provinces in both periods 1 and 2 than in the treated provinces. Even though, the growth rate of real wages in Alt_5084 provinces decline between Period_0 and Period_1, they still experience positive growth as opposed to none in $D \_5084$ provinces. Alt_5350 provinces, on the other hand, have the same pattern of change as $D \_5350$ provinces.

Before moving on to the results of our econometric analysis, it may be useful to visualize some of the results by presenting the month-to-month evolution of outcomes in treatment versus control provinces. Figure 3 illustrates graphically the impacts of Law 5084 and 5350 on treated provinces (D_5084 and D_5350) compared to the alternative control provinces (Alt_5084 and Alt_5350). ${ }^{17}$ These figures also provide visual evidence on the comparability of trends in outcomes between treatment and control groups in the pre-treatment period.

Figures 3(a) and 3(c) illustrate the effects of Law 5084. These figures present the average employment and number of establishments separately for D_5084 and Alt_5084 provinces. It is quite clear that both employment and establishments in $D \_5084$ provinces increase at a much faster rate compared to Alt_5084 provinces shortly after January 2004 when Law 5084 came into effect.

Figures 3(b) and 3(d) present comparable trends for D_5350 and Alt_5350 provinces. Although the period covered is short, these graphs still show some evidence of the law having an effect, especially on employment. Figure 3(b) shows that, while during Period_0 and Period_1 employment in D_5350 provinces followed a similar path with the Alt_5350 provinces, after May 2005 when Law 5350 was enacted, employment in D_5350 provinces started growing at a higher rate than in the control provinces. The effect of Law 5350 on workplaces seems to be much smaller, lending support to our expectation that Law 5350 would yield larger effects at the intensive rather than extensive margin.

\footnotetext{
${ }^{17}$ We present figures with alternative control provinces since these groups are statistically found to be similar to the treated ones. Similar figures using the remaining control groups confirm our analysis in this section.
} 


\section{$5 \quad$ Econometric Results}

We move next to describing the results of estimating specifications 3 and 4 which are summarized in Tables 7, 8, and 9 for employment, number of establishments, and wages, respectively.

\subsection{Employment}

The left panel of Table 7 presents the estimates for the effect of Law 5084 on employment for three different control groups, and four alternative specifications. Focusing first on the first top panel, which uses provinces D_never as control, and first column, which presents the results of a specification with period and group dummies as described in specification 3, the coefficient on the interaction between the variables D_5084 and Period_1 is positive and statistically significant, indicating that after the introduction of subsidies, employment in provinces $D \_5084$ increased by $5 \%$ more in the treated than in the control provinces.

Results do not change if the specification is augmented with a full set of province and date dummies (column 2). Similarly, allowing for province-specific time trends yields positive and statistically significant effects of the subsidies (column 3). The magnitude of the coefficient, however, becomes larger, suggesting that Law 5084 subsidies boosted employment in the D_5084 provinces by almost $8 \%$ above the level in the control (D_never) provinces.

Similarly, the story remains when employment growth, rather than employment levels, is specified as the dependent variable (column 4). The coefficient on the D_5084*Period_1 interaction suggests that in Period 1, Law 5084 increased employment growth in the treated provinces by 1 percentage point a month relative to the control.

The middle left panel of Table 7 shows the estimates using D_5350 provinces as the control group for the effect of Law 5084. Results again suggest subsidies provided a significant boost to employment levels and growth in D_5084 provinces. The coefficient on the interaction term D_5084* Period_1 in columns (1)-(3) is positive and statistically significant in all but in the specification with province-specific time trends. Nonetheless, the coefficients on the growth regressions (column 4) appear positive and statistically significant which suggests that the lack of significance in column 3 may be due to insufficient degrees of freedom. ${ }^{18}$ The implied magnitudes are sizable: in Period 1, employment in the treated provinces would

\footnotetext{
${ }^{18}$ Province-specific trends become province-fixed effect after taking first differences of specification in column (2).
} 
have increased by $12.7 \%$ above the D_5350 control group in two of the three specifications. In terms of growth rates, the estimated effect of the subsidies amounts to 1.8 percentage points per month.

The bottom left panel of Table 7 presents results with the alternative control group, constructed to match pre-treatment trends in the treated provinces. Results indicate positive and statistically significant effects across all specifications, of a magnitude that lies between those obtained with $D \_n e v e r$ or D_5350 provinces as control.

The right panel of Table 7 presents the estimated effects of Law 5350 on the employment of D_5350 provinces, using the never subsidized provinces (top panel) or Alt_5350 (bottom panel) as control groups. Estimated effects are positive, statistically significant and very similar in either case, regardless of whether the specification includes period and group dummies only (column 5), or is augmented with a full set of month dummies (column 6) or province-specific time trends (column 7).

As expected, we estimate larger effects of Law 5350 relative to Law 5084. For, example, the coefficients obtained using the alternative controls and a specification with a full set of province and time dummies, yield an effect of Law 5350 on employment of $11 \%$ relative to an effect of Law 5084 of $8.6 \%$. The comparable magnitudes obtained when using the never treated provinces as control are $14.2 \%$ versus $8.1 \%$. Obviously these larger effects need to be assessed against costs estimates of both programs. We retake this issue in section 7 .

Taken together, these results suggest a positive, sizable, and statistically significant effect of the regional subsidies on employment levels and growth in the covered provinces, with the magnitude of the effect greater for Law 5350. Regarding Law 5084, the estimated magnitude of the effect is larger when D_5350 provinces are considered as control group. While 5350 provinces are more similar to the D_5084 group than never provinces, the larger effects may be capturing substitution effects. It is plausible that the subsidies motivate some firms to change locations, or shift jobs across similar and geographically close provinces in order to gain access to the subsidies.

\subsection{Number of establishments}

We next turn to examining how subsidies affected the number of establishments. Results are presented in Table 8, which is organized in the same fashion as Table 7. The left panel provides the estimates of the effects of Law 5084 and the right panel the results for Law 
5350. Each row panel provides estimates for a different control group.

Assessing first the effects of Law 5084, results indicate that relative to the never subsidized provinces, the number and growth rate of establishments increased in provinces D_5084 as a result of Law 5084 (as indicated by a positive and statistically significant coefficient on D_5084* Period_1 in columns (1)-(4)). The estimates suggest that the subsidies increased the number of establishments by between $2.5 \%$ and $4.1 \%$ above the control group, while the establishment growth rate increased by about 0.5 percentage points.

Similar results are obtained if $D \_5350$ or Alt_5084 provinces are used as control groups, with the exception that the coefficients on column (3) are not statistically significant. Nonetheless, estimates are positive and statistically significant when the dependent variable is the growth of workplaces, suggesting again that the lack of statistical significance in column(3) may be due to insufficient degrees of freedom.

Regarding Law 5350, we find mixed evidence of its effects on the number of establishments. Controlling only for time and province indicators does not yield a statistically significant effect (columns 1 and 2), regardless of the control group used. Adding province-specific time dummies yields a positive and statistically significant coefficient on the interaction term, which also appears in the growth regressions, suggesting that Law 5350 would have increased the growth in the number of workplaces by 0.3 percentage points. Lastly, results are even more mixed when using the Alternative control group, with statistically significant results only for the specification with province-specific time trends. Thus, assessments on whether Law 5350 increased the number of establishments in 5350 provinces depend to great extent on which specification and control group is chosen. Considering that the constructed control group matches pre-treatment trends, it can be argued that specification (2) is an appropriated model, in which case, it could be tentatively concluded that law 5350 had a lower impact on the number of establishments than Law 5084 and that most of the results of Law 5350 on employment were on the intensive rather than the extensive margin.

As with employment, we also find the effects of Law 5084 to be more sizable if D_5350 provinces are used as a control group, which again could indicate some substitution effects across provinces. All in all, our results suggest that Law 5084, and more tentatively Law 5350 , had a positive effect in the number and growth of workplaces in the treated provinces. Such effects could be driven by either higher expected profits or firms' incentives to outsource workers to eligible firms in order to claim marginal benefits. The evidence also suggests that 
such incentives would have been reduced in the second law, as the size and significance of the estimated effects on the number of establishments tends to be lower, despite sizable effects on employment. As predicted by Figure 1, Law 5350 would have led to higher employment growth per firm. Combining the results in Tables 7 and 8 (columns 2 and 6) using the alternative controls, we find that Law 5084 and Law 5350 increased the number of workers per establishment by $3.7 \%$ and $10 \%$, respectively. In other words, growth at the intensive margin was the most important part of the overall effect of these regional incentive program, particularly in the case of Law 5350.

\subsection{Earnings}

Finally, we examine the effects of the subsidies on earnings (Table 9). As discussed in section 2 , there is substantial agreement in the literature that taxes on wages are, to a large extent, shifted on to workers in the form of lower wages. The same logic would indicate that, assuming symmetry, employment subsidies are expected to be at least partially shifted back to workers as wage increases. As discussed in section 4, we do not have data on individual wages or earnings. Instead, we approximate earnings per worker by dividing total taxable earnings by the number of workers in each province. ${ }^{19}$

Subjecting the wage data to the same menu of specifications and control groups analyzed for employment and number of establishments provides little evidence of wage shifts. Regardless of the specification or the control group, we never find positive and statistically significant coefficients on the interaction terms. In fact, focusing first on Law 5084, the growth specification (column 4) yields coefficients that are negative and statistically significant. The evidence then suggests that subsidies either had no effect on wages or, if there was an effect, it was negative.

Regarding Law 5350, the evidence points even more strongly to negative and statistically significant effects on taxable earnings. The only exception is given by the coefficients in column 8, which are positive but not statistically different from zero.

These results run counter to those found by Taymaz (2006) for Turkey, where based on an analysis of manufacturing data, he finds strong evidence of a wage pass-through. His findings,

\footnotetext{
${ }^{19}$ Due to a maximum and a minimum in the taxable earnings base, taxable earnings and earnings differ in the low and upper part of the distribution. This implies, for example, that if wage shifts occur only at the upper end of the distribution we would not capture it.
} 
however, also indicate that the pass-through is substantially reduced for wages around the minimum wage. One possible explanation for our results, then, is that minimum wages are binding in subsidized regions and therefore, the pass-through for low-wage workers is low. Table 10 shows that average taxable earnings are lower and closer to the minimum wage in D_5084 and D_5350 provinces than in the never-treated provinces, but our data do not allow us to infer whether minimum wages are effectively binding. Another possible explanation is that subsidies-which are set at minimum wage/contribution base levels-stimulate firms to hire workers with relatively lower earnings and that, as a result, on average, taxable earnings decline. The larger negative effect of law 5350, coinciding with larger employment effects, lends support to this hypothesis. Unfortunately, the data do not allow us to test directly these effects.

\subsection{Anticipation of Laws}

One potential problem in our analysis is that the assumptions underlying difference-indifferences estimates are invalid if employers expect the enactment of subsidy laws and strategically delay hiring new workers or creating new establishments until after the law is introduced. In this case, our estimates would be upward biased. In order to address this issue, we use an interrupted panel strategy. The intuition is that, by dropping a few months of data before and after the enactment of each law, we can mitigate the effect of such strategic responses by eliminating periods when employers have the highest incentive to shift the creation of jobs and firms. However, we do not conduct such analysis for Law 5350 due to the short span of the post-treatment period for that law (Period_2) covered by our data.

In order to check the robustness of our estimates for Law 5084, we re-run specification 3 after dropping the three months before and after the enactment of the law. Hence, in this case, Period_0 covers the period between April 2002 to September 2003 and Period_1 covers the period between April 2004 to April 2005. ${ }^{20}$ Table 11 provides the results of these interrupted panel estimations. The results change little when applying the interrupted panels,

\footnotetext{
${ }^{20}$ Recall that Law 5084 subsidizes all registered employment in establishments created on and after October 2003, while for establishments that started operations before that date, subsidies are calculated based on the number of workers over and above those registered with social security on the reference date (August 2003). If employers strategically lowered employment on the reference date or postponed job creation around October 2003 to get subsidies for all of their workers, dropping the three months before the start of Law 5084 might not be enough to remove strategic behavior of employers. For that reason, we also tried an alternative specification where we dropped the 6 months before and 3 months after Law 5084 with very similar results.
} 
with virtually no qualitative difference from our original estimates. Quantitatively, interrupted panel regressions yield somewhat larger estimates in absolute terms, which suggests that an upward bias resulting from strategic responses of employers is unlikely and that our difference-in-differences estimates do capture the real effects of the subsidy law.

The first column of table 11 shows that, on average, during period 1 employment increased by 4.4 to $13.2 \%$ more in $D \_5084$ provinces than in the control provinces. Similarly, our results suggest that in Period 1, Law 5084 increased employment growth in the treated provinces by 1.1-2.6 percentage points a month.

Columns 3 and 4 provide results for the number of establishments. As in the case of employment, we find the effect of Law 5084 to be larger under these specifications: the number of establishments increased by between $0.4 \%$ and $5.3 \%$ above the control provinces, while the establishment growth rate increased by about 1 percentage point.

Finally, the last two columns of the table confirm our previous conclusions on real average taxable earnings that the subsidies had either no effect on wages or a negative effect. The magnitude of the effect of the law are larger in these later regressions suggesting, at their lowest estimate, a reduction of $1.7 \%$ in the treated provinces compared to the control provinces.

Larger effects in the interrupted panel for employment and establishments suggest the effects of the program pick up after a few months of operation. This is also consistent with more negative effects on taxable earning in the interrupted panel.

\section{Formalization versus Job Creation}

Taken together, the estimates presented in the previous section suggest that the different subsidy packages had important effects in stimulating the growth of registered employment and registered establishments in low-income regions of Turkey. Unfortunately, these data do not allow us to determine whether these increases actually represented new jobs or establishments or, instead, resulted from the formalization of previously non-registered (informal) employment and firms. To investigate this issue, ideally we would require household data on total employment - formal and informal - by province and period. Unfortunately, we do not have access to province identifiers in household data and, therefore, it is not possible to look at the evolution of formalization versus total employment generation in this way. 
Another possible approach is to examine whether economic activity has increased in the treated relative to the control provinces. Unfortunately, province-level GDP data for the period of analysis were not yet available. As an alternative approach, we analyze electricity consumption data. Since electricity cannot be stored, its consumption is closely correlated with the level of economic activity and is a commonly used proxy for economic activity. If registered employment and establishment gains reflect an actual increase in total employment and number of establishments, then economic activity would have increased and, therefore, the consumption of energy should have increased as well. Since monthly electricity data per province are not available, we estimate the model with annual data for the period 2002-2004. We examine this hypothesis by estimating the following specification ${ }^{21}$ :

$$
\begin{aligned}
Z_{j t} & =\varphi_{0}+\varphi_{1} D \_p o s t+\varphi_{2} D \_4325+\varphi_{3} D \_5084+\varphi_{4} D \_5350 \\
& +\varphi_{5} D \_4325 * D \_p o s t+\varphi_{6} D \_5084 * D \_p o s t+\varphi_{7} D \_5350 * \text { D_post }+\xi_{j t}
\end{aligned}
$$

where $Z_{j t}$ is consumption of electricity, $D_{-}$post is the post-treatment period (i.e., year 2004), and the rest of the variables are as described before. The coefficient on the D_5084* D_post variable measures the differential change in electricity consumption during the posttreatment period in provinces D_5084 relative to D_never provinces. A positive and significant coefficient on this variable would be consistent with the hypothesis that employment created because of the subsidies was due to an increase in economic activity.

As shown in Table 12, the estimates suggest that electricity consumption did not increase after the enactment of Law 5084. It should be recognized that data availability is a limiting factor since we are only able to use three observations per province, with only one after Law 5084 was introduced. Moreover, subsidies were paid only for the last 10 months of that year. While these results are limited by the factors noted above, they suggest that the gains in employment and number of firms correspond to a surge in formalization, rather than to real gains in economic activity.

\footnotetext{
${ }^{21}$ We also estimated specifications based on 3 with annual data and the the alternative control groups with very similar results.
} 


\section{Cost of the programs}

We next analyze the expenditure side of the regional incentives programs in order to estimate the cost of formal job creation. The calculation of the costs incurred under the programs includes the social security, income tax, and energy subsidies. The social security costs are provided in the SSK database. The income tax costs, while not directly available, can be estimated as a proportion of the social security subsidies. ${ }^{22}$ The costs of the energy subsidies are obtained from Treasury data. Land has not been included in the cost calculations because neither data nor a method for approximating these costs is available. Hence, our estimates of total costs are downwardly biased.

Expenditures under Law 5084 and estimates of the cost per job are presented in Table 13. These cover the 14-month period from March 2004, when the first subsidies were paid, to April 2005, the last month before Law 5350 came into effect. Four calculations have been made to estimate the cost per job. The first divides the total cost of the subsidies by the number of subsidized "job-months" as reported in the SSK administrative files during the period. ${ }^{23}$ In effect, this computation assumes that each subsidized job-month was actually created due to the subsidy. A comparison of the total number of jobs subsidized with the total number of jobs created as estimated through our models provides an estimate of the "deadweight loss" - i.e., the number of jobs that were unnecessarily subsidized. The other three calculations compute the cost per "net" job-month created, using our econometric modeling results to determine how many jobs were actually created because of the program. These three calculations are based on a low, a medium, and a high estimate of the effects.

According to the SSK files, 739,757 "job-months" were subsidized under Law 5084 in all the D_5084 provinces. The table also shows that our estimate of the total subsidy cost - based on the social security and energy subsidy data and our derived estimate of the income tax

\footnotetext{
${ }^{22}$ In order to calculate the income tax subsidy, we assumed that everyone who got the social security subsidy also got the income tax subsidy. The income tax rate on the minimum wage was $15 \%$. So, income subsidy $=(\#$ eligible workers $) *(100 \text { or } 80 \%)^{*}($ minimum wage $) * 15 \%$. It is also described in the laws that the amount of SSK subsidy was calculated as: SSK subsidy=(\#)ligible workers)*(100 or 80\%)*(contribution base)*20.5\%. Hence, one can calculate the amount of total income tax subsidy received as a fraction of the SSK subsidy received. For the period April 2002 to June 2004, income subsidy $=0.56 *$ social security subsidy as the contribution base differs from the minimum wage. For the period July 2004 to December 2005: income subsidy $=0.73^{*}$ social security subsidy as the contribution base equals the minimum wage.

${ }^{23}$ A "job-month" refers to a worker who has been subsidized during a particular month. We refer to job-months rather than jobs because the SSK data are provided on a monthly basis.
} 
subsidy - was 112,275,769YTL (New Turkish lira). This implies that the cost per job-month was 152YTL. During the months when Law 5084 subsidies were being paid, the average monthly labor cost for a minimum wage worker was 548YTL. So the cost per job-month, based on the number of subsidized jobs, was about $28 \%$ of the total labor cost for a minimum wage worker at that time. ${ }^{24}$ If this was the end of the story, it could be argued that this is a relatively low cost for creating jobs. However, our econometric estimates indicate that only a small portion of the subsidized jobs was actually created because of the incentives, which substantially reduces the cost-effectiveness of the program. Depending on the actual estimate of the employment impact, somewhere between $47 \%$ and $78 \%$ of the subsidized jobs under Law 5084 would have been created without the program. ${ }^{25}$ As a result of these substantial deadweight losses, costs per job-month range from 678YTL with our low estimate of jobs created to 286YTL for the upper-end estimate. These subsidy amounts represent roughly $124 \%$ and $52 \%$, respectively, of the average monthly cost of a minimum-wage worker. Using the mid-range estimate of employment generation, the cost per job-month is 408YTL, about $74 \%$ of the total cost of employing a minimum-wage worker. ${ }^{26}$

Similarly, Table 14 provides the cost estimates for Law 5350. These cover the 8-month period from May 2005 when the first subsidies were paid under the new law to December 2005, the last month for which we have data. According to the SSK files, 368,551 job months were subsidized under this law in the D_5350 provinces. The table shows our estimate of the total cost of 92,970,931YTL. This means the cost per subsidized job-month was 252YTL, which was about $42 \%$ of the total labor cost for a minimum wage worker during this period (594YTL). Comparing this figure to that of cost per subsidized job under Law 5084 shows that the level of subsidies was considerably larger under the rules of Law 5350. However, once deadweight losses are taken into account, Law 5350 turns out to be more cost-effective.

\footnotetext{
${ }^{24}$ Since the potential size of the subsidies for all of the different components is significantly higher than that, it seems that a significant proportion of subsidized employees worked less than a full month and/or worked part-time.

${ }^{25}$ Our estimates are likely to overestimate the number of job-months created by the program as they assume that all jobs created were subsidized from the first month the program was in effect. Yet, as suggested by our interrupted panel estimates, the effect of the subsidies may have picked up a few months after the beginning of the program, which implies that the average duration of the subsidy for each worker is lower than the length of the period in which the subsidy was in effect.

${ }^{26}$ This comparison is less meaningful if beneficiary workers earned wages above the minimum. However, the fact that average earnings declined as a result of the program and that the maximum subsidy is attained for workers earning minimum wages suggest that most beneficiaries earned wages around the minimum.
} 
Our empirical results suggest that, depending on the specification, between $23 \%$ and $44 \%$ of the jobs subsidized under Law 5350 would have been created without the subsidy. These deadweight losses, although by no means insignificant, are much lower than those estimated for Law 5084. Accordingly, the costs per actual job created are much lower as well. We calculate the cost per job-month created under low-end job creation estimate at 449YT and at 329YTL for our higher job estimate. These represent $76 \%$ and $55 \%$ of the total cost of a minimum wage worker, respectively.

The former calculations assume that the programs create new jobs. If it turns that the programs increase registration rather than actual job creation, as suggested by the electricity estimates, the benefits of the program would be much lower. In this case, it would only entail the expansion of basic health and pension coverage and perhaps higher wages for workers who switch to formal jobs, if they were previously employed in less productive informal jobs. Finally, it should be noted that the estimated costs of the program are only lower bounds of real costs as they do not include the cost of possible substitution effects, the administrative costs of implementing and supervising the programs, or the costs incurred by the government to provide pension and health services to newly registered workers.

We draw two conclusions from this cost analysis. First, deadweight losses associated with the program are important, but the design of the program clearly matters as it appears that the eligibility thresholds significantly reduced deadweight losses, by promoting higher employment gains per workplace and, possibly, reducing the artificial shift of workers to newly created workplaces. Because deadweight losses were much smaller under Law 5350 than under Law 5084, the actual cost of jobs under the newer program was considerably less

even though the financial outlay per subsidized worker was higher. Second, the possibility that in developing countries marginal job subsidies do not increase total employment, but rather, increase formalization, substantially alters the cost-benefit analysis. There might be alternative, more cost-effective, ways to extending basic pension and health services to a larger pool of workers.

\section{Conclusions}

In this paper we examine the benefits and costs of subsidizing the cost of low-income workers in economically disadvantaged regions of Turkey. We take advantage of a series of consecutive 
programs, with widening regional coverage, to implement a pseudo-experimental approach. This allows us to compare the evolution of employment, number of establishments, employment per firm, taxable earnings per worker, and consumption of electricity before and after the different subsidies came into effect. Our results point to a substantial elasticity of employment to changes in labor costs. They also indicate that establishment creation is quite responsive to changes in labor costs and labor taxes particularly when minimum wages or other constraints may reduce pass through rates. All of these findings suggest the importance of labor costs as a factor in determining employment creation both in the intensive and the extensive margin.

Nonetheless, our results also suggest that implementing the subsidies can be a costly way to increase employment. Under Law 5084, the subsidies likely ended up paying for almost the full labor costs of the jobs created, rather than subsidizing employment at the margin. The main issue was deadweight losses - i.e., that many subsidized jobs would have been created anyway - which increased considerably the real cost of the program. This is particularly a concern in Turkey given that the subsidies analyzed in this study were implemented in a period in which economic growth was picking up after a crisis and firms likely were prepared to hire new workers in any event. Law 5350 also had deadweight losses but these were considerably smaller than those under the previous law. So, even though the subsidies themselves were more generous, the program turned out to be more cost effective.

A final, and key consideration is that although we were only able to undertake an imperfect test, our results suggest that subsidies increased formalization of existing firms and jobs rather than creating new economic activity. This is a relevant distinction and deserves close attention in future studies. If confirmed, it would alter the cost-benefit calculations of the program, as it would not imply new economic activity, but rather an extension in the coverage of social security programs. This would support the hypothesis that in countries with relatively weak enforcement institutions, high labor taxes on low-wage workers create a strong incentive for informality both for firms and workers. From that point of view, exempting (fully or partially) low-wage workers from income and social security taxes may be an effective way to reduce informality and expand the coverage of basic health and old age pension benefits to the labor force. Such exemptions are not unlike those found in many income tax systems in the world, where there is a certain minimum income that is exempted and/or where tax rates are progressively set. 


\section{References}

Autor, David, John Donohue III, and Stewart Schwab (2006), "The Cost of Wrongful Discharge Laws," The Review of Economics and Statistics 88, 211 - 231.

Autor, David H., William R. Kerr, and Adriana D. Kugler (2007), "Does Employment Protection Reduce Productivity? Evidence from US States," The Economic Journal 117, F189 - F217.

Bertrand, Marianne, Esther Dufflo, and Sendhil Mullainathan (2004), "How much should we trust difference in differences estimates?" Quarterly Journal of Economics 119, 249-275.

Besley, Timothy, and Robin Burgess (2004), "Labor Regulation Hinder Economic Performance? Evidence From India," Quarterly Journal of Economics 119, 91-134.

Bishop, John (1981), Studies in Labor Markets, chap. Employment in Construction and Distribution Industries: The Impact of the New Jobs Tax Credit, 209-46, University of Chicago.

Evans, William N., and Diana S. Lien (2005), "The benefits of prenatal care: evidence from the PAT bus strike," Journal of Econometrics 125, 207-239.

Galasso, Emanuela, Martin Ravallion, and Agustin Salvia (2001), "Assisting the Transition from Workfare to Work: A Randomized Experiment," The World Bank, Policy Research Working Paper Series No. 2738.

Gerfin, Michael, Michael Lechner, and Heidi Steiger (2005), "Does subsidised temporary employment get the unemployed back to work? An econometric analysis of two different schemes," Labour Economics 12, 807835.

Girma, Sourafel, Holger Grg, Eric Strobl, and Frank Walsh (2007), "Creating jobs through public subsidies: An empirical analysis," forthcoming Labour Economics.

Gruber, Jonathan (1997), "The Incidence of Payroll Taxation: Evidence from Chile," Journal of Labor Economics 15, 72-101.

Hamermesh, Daniel (1993), Labor Demand, Princeton University Press. 
Heckman, James, and Carmen Pagés (2004), Law and Employment: Lessons from Latin America and the Caribbean, chap. Introduction to Law and Employment: Lessons from Latin America and the Caribbean, National Bureau of Economic Research University of Chicago Press.

Katz, Larry (1998), Generating Jobs: How to Increase Demand for Less Skilled Workers, chap. Wage subsidies for the Disadvantaged, Russell Sage Foundation.

Marx, Ive (2005), "Job Subsidies and Cuts in Employers Social Security Contributions: The Verdict of Empirical Evaluation Studies," Presented at "Changing Social Policies for Low-Income Families and Less-Skilled Workers in the E.U and the U.S.", University of Michigan.

Mühlau, Peter, and Wiemer Salverda (2000), Policy Measures for Low-Wage Employment in Europe, chap. Employment effects of low-wage subsidies: The case of "SPAK" in the Netherlands, Edward Elgar.

Nickell, Stephen (2003), "Employment and Taxes," CESifo Working paper No.1109.

OECD (2003), Employment Outlook, Paris.

Papps, Kerry (2007), "The Effect of Social Security Taxes and Minimum Wages on Employment Growth in Turkey," Mimeo, the World Bank.

Taymaz, Erol (2006), "Labor Demand in Turkey," Mimeo, the World Bank.

World Bank (2006), "Country Economic Memorandum: Promoting Sustained Growth and Convergence with the European Union," Tech. rep. 


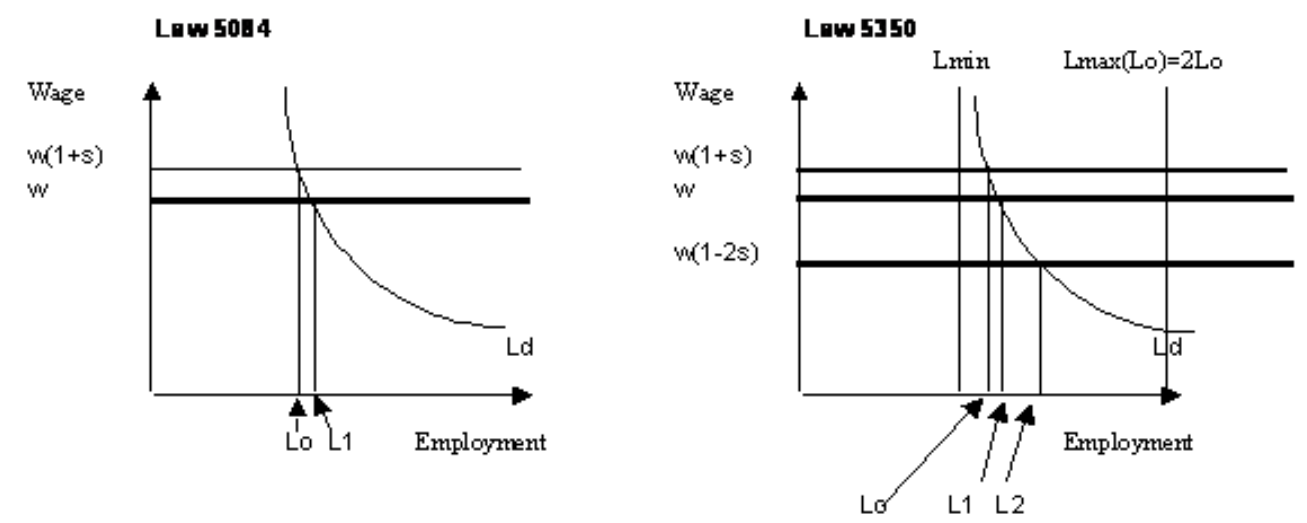

Figure 1: The employment effects of Law 5084 versus Law 5350

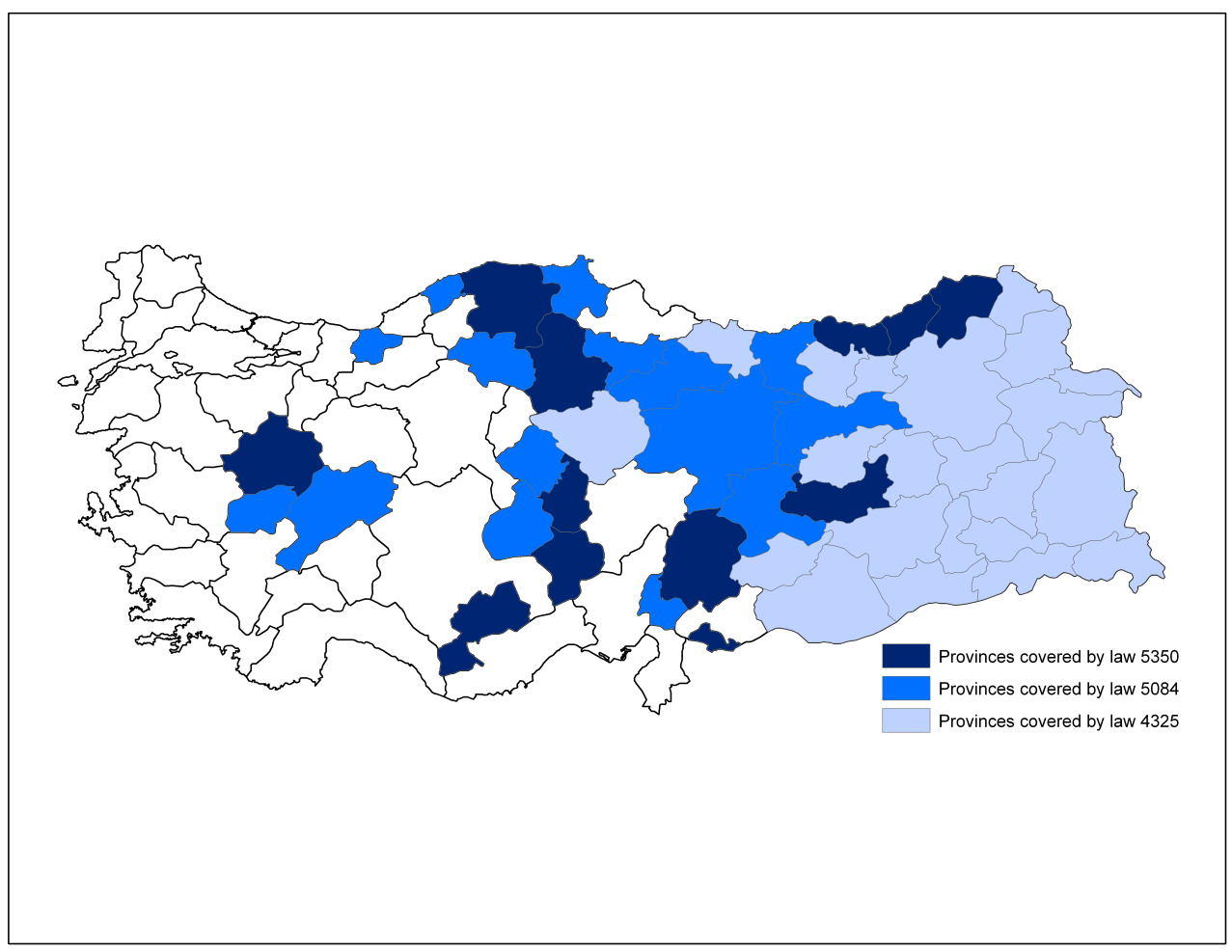

Figure 2: Location of provinces covered by laws 


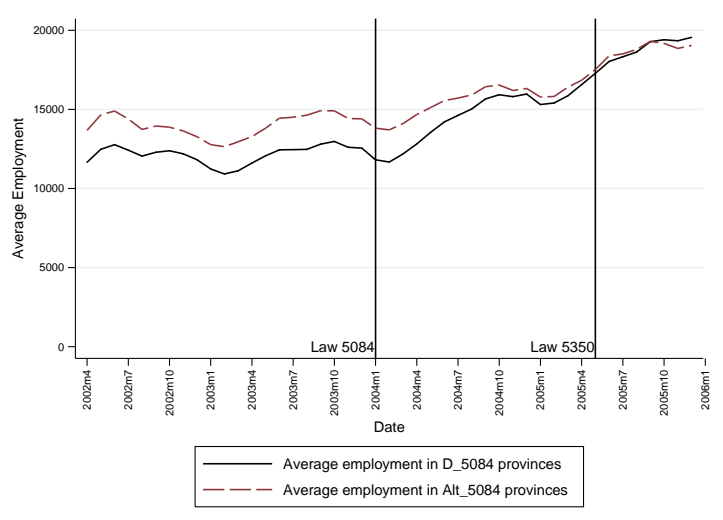

(a) Employment in D_5084 and Alt_5084

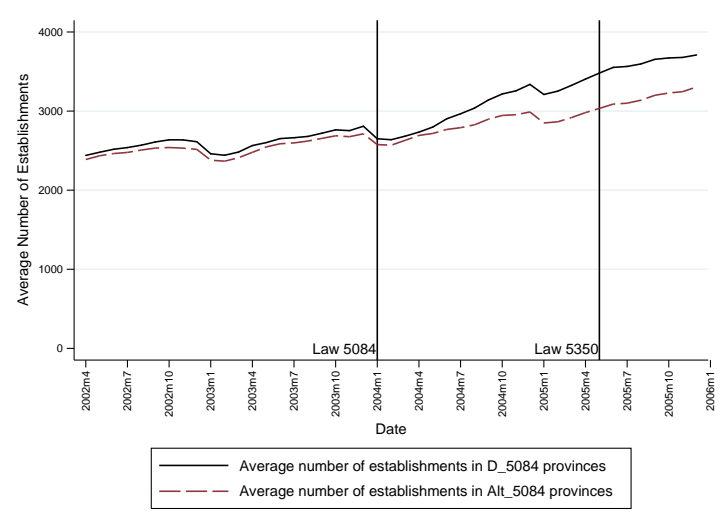

(c) Establishments in D_5084 and Alt_5084

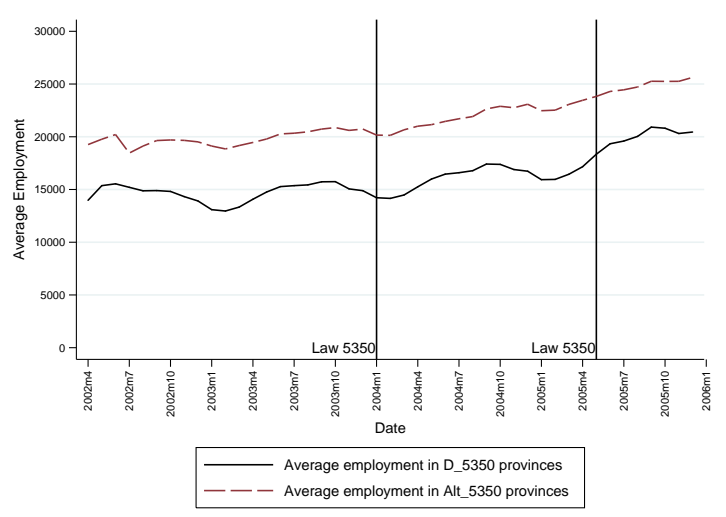

(b) Employment in D_5350 and Alt_5350

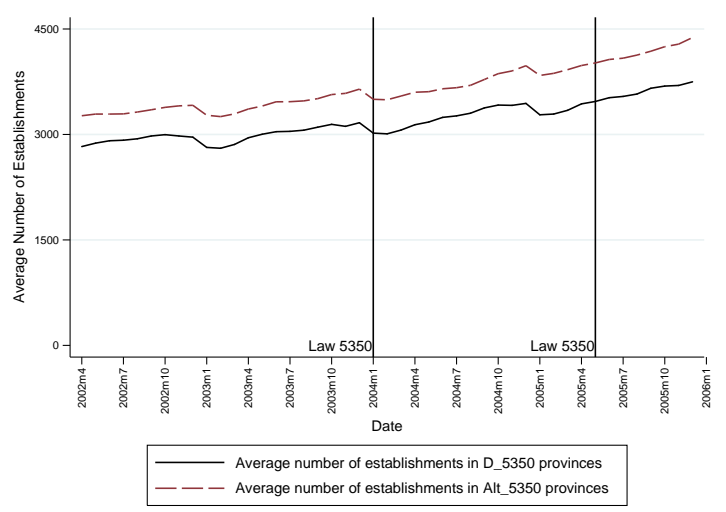

(d) Establishments in D_5350 and Alt_5350

Figure 3: Evolution of outcomes in treatment and control groups 


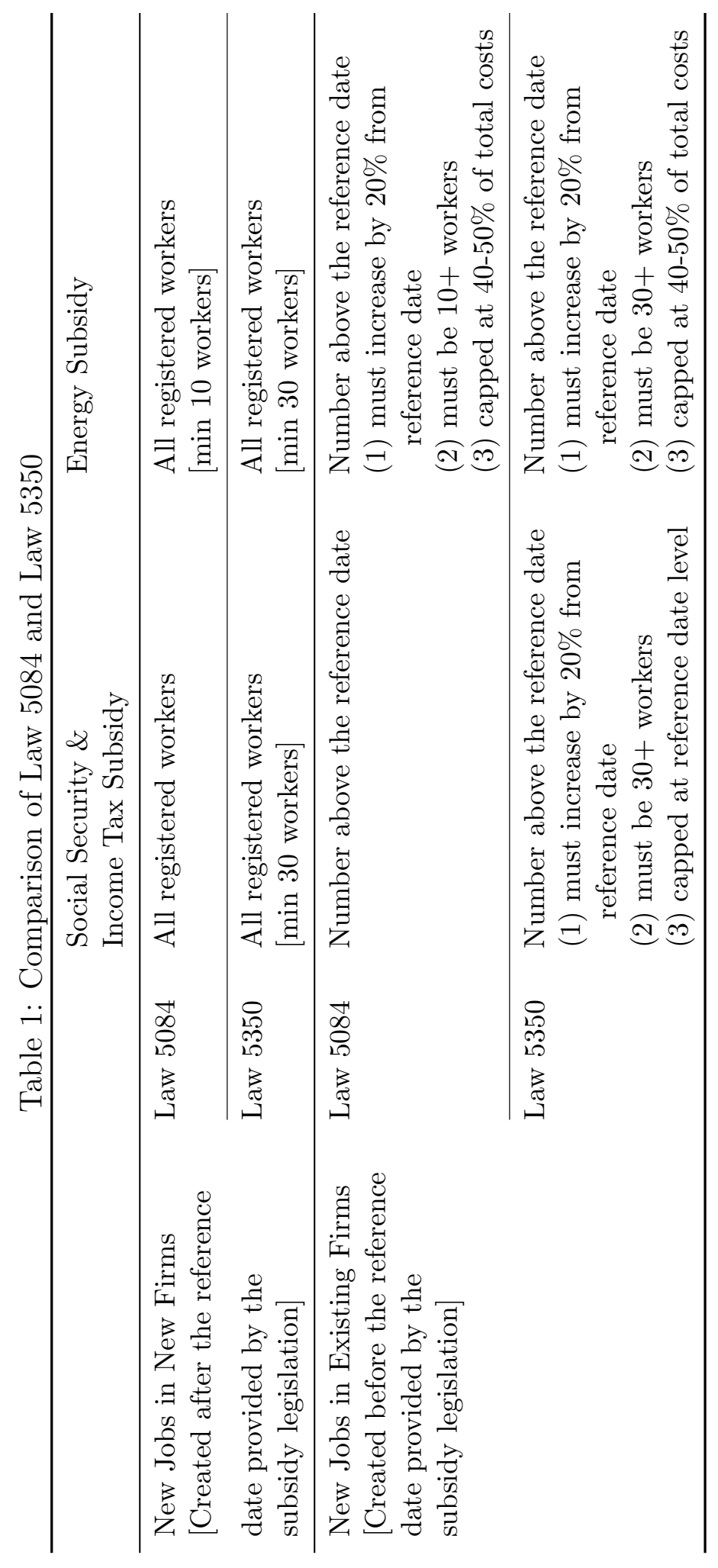


Table 2: Summary statistics of key variables (province-month as unit observation)

\begin{tabular}{lccc}
\hline Variable & Obs & Mean & Std. Dev. \\
\hline Employment & 3555 & 65,831 & 216,343 \\
Workplaces & 3555 & 9,782 & 28,286 \\
Taxable earnings (YTL) & 3555 & $39,944,968$ & $153,574,145$ \\
SSK subsidy provided under Law 5084 (YTL) & 675 & 153,739 & 213,318 \\
SSK subsidy provided under Law 5350 (YTL) & 585 & 47,354 & 156,905 \\
Energy subsidy (YTL) & 700 & 185,594 & 358,826 \\
\hline
\end{tabular}

Note: Summary statistics for employment, workplaces and taxable earnings are calculated for the full sample (79 provinces during April 2002 to December 2005). SSK subsidy statistics are calculated using the sample of provinces covered by the corresponding law for the period April 2002 to December 2005. Statistics for the energy subsidy are calculated using all subsidized provinces for the period January 2004 to December 2005 when the data are available.

Table 3: Comparison of groups of provinces

\begin{tabular}{llcccc}
\hline & & \multicolumn{4}{c}{ Provinces } \\
\cline { 3 - 6 } & & $D \_4325$ & $D \_5084$ & $D \_5350$ & D_never \\
\cline { 3 - 6 } GDP per capita & mean & 941.14 & 1355.6 & 1798.38 & 2545.31 \\
(USD 2001) & sd & 242.34 & 222.88 & 199.94 & 928.32 \\
\hline Electricity consumption & mean & $338,098.8$ & 350,365 & $470,507.6$ & $2,756,096$ \\
(MWH, 2002-2004) & sd & $337,426.7$ & $201,610.2$ & $406,888.3$ & $3,809,520$ \\
\hline Population per & mean & 53.18 & 76.4 & 63.85 & 176.88 \\
km2 (2000) & sd & 31.25 & 67.68 & 52.19 & 333.52 \\
\hline
\end{tabular}

Notes: Data on GDP per capita and electricity consumption are provided by the Turkish Statistical Institute. Data on population density comes from the 2000 Census. D_4325 contains the 22 provinces that were subsidized under Law 4325; D_5084 includes the 15 provinces that were subsidized under Law 5084 but not covered by Law 4325; D_5350 contains the 13 provinces that were subsidized by Law 5350 but not covered by Law 5084. In that way, each group only includes the eligible provinces added under each consecutive law. D_never contains the provinces that were not subsidized under any law. 
Table 4: Summary statistics for registered employment growth

\begin{tabular}{|c|c|c|c|c|c|}
\hline & & $\begin{array}{c}\text { Full Period } \\
\text { (April 2002- } \\
\text { December 2005) }\end{array}$ & $\begin{array}{c}\text { Period 0 } \\
\text { (April 2002- } \\
\text { December 2003) }\end{array}$ & $\begin{array}{c}\text { Period } 1 \\
\text { (January 2004- } \\
\text { April 2005) }\end{array}$ & $\begin{array}{c}\text { Period } 2 \\
\text { (May 2005 } \\
\text { December 2005) }\end{array}$ \\
\hline \multirow{2}{*}{$\begin{array}{l}\text { All } \\
\text { provinces }\end{array}$} & mean & 0.013 & 0.008 & 0.016 & 0.020 \\
\hline & $\mathrm{sd}$ & 0.088 & 0.101 & 0.085 & 0.046 \\
\hline \multirow{2}{*}{$\begin{array}{l}D \_5084 \\
\text { provinces }\end{array}$} & mean & 0.013 & 0.004 & 0.020 & 0.023 \\
\hline & $\mathrm{sd}$ & 0.042 & 0.045 & 0.043 & 0.029 \\
\hline \multirow{2}{*}{$\begin{array}{l}D \_5350 \\
\text { provinces }\end{array}$} & mean & 0.013 & 0.012 & 0.010 & 0.026 \\
\hline & $\mathrm{sd}$ & 0.124 & 0.173 & 0.060 & 0.052 \\
\hline \multirow{2}{*}{$\begin{array}{l}\text { D_never } \\
\text { provinces }\end{array}$} & mean & 0.010 & 0.007 & 0.013 & 0.012 \\
\hline & $\mathrm{sd}$ & 0.078 & 0.062 & 0.107 & 0.031 \\
\hline \multirow{2}{*}{$\begin{array}{l}\text { Alt_5084 } \\
\text { provinces }\end{array}$} & mean & 0.008 & 0.002 & 0.011 & 0.018 \\
\hline & $\mathrm{sd}$ & 0.040 & 0.044 & 0.036 & 0.038 \\
\hline \multirow{2}{*}{$\begin{array}{l}\text { Alt_5350 } \\
\text { provinces }\end{array}$} & mean & 0.007 & 0.005 & 0.008 & 0.012 \\
\hline & $\mathrm{sd}$ & 0.040 & 0.054 & 0.024 & 0.015 \\
\hline
\end{tabular}

Table 5: Summary statistics for registered workplace growth

\begin{tabular}{|c|c|c|c|c|c|}
\hline & & $\begin{array}{c}\text { Full Period } \\
\text { (April 2002- } \\
\text { December 2005) }\end{array}$ & $\begin{array}{c}\text { Period 0 } \\
(\text { April 2002- } \\
\text { December 2003) }\end{array}$ & $\begin{array}{c}\text { Period } 1 \\
\text { (January 2004- } \\
\text { April 2005) }\end{array}$ & $\begin{array}{c}\text { Period } 2 \\
\text { (May 2005 } \\
\text { December 2005) }\end{array}$ \\
\hline \multirow{2}{*}{$\begin{array}{l}\text { All } \\
\text { provinces }\end{array}$} & mean & 0.009 & 0.007 & 0.010 & 0.013 \\
\hline & $\mathrm{sd}$ & 0.032 & 0.034 & 0.033 & 0.024 \\
\hline \multirow{2}{*}{$\begin{array}{l}D \_5084 \\
\text { provinces }\end{array}$} & mean & 0.010 & 0.007 & 0.013 & 0.011 \\
\hline & sd & 0.024 & 0.023 & 0.028 & 0.013 \\
\hline \multirow{2}{*}{$\begin{array}{l}D \_5350 \\
\text { provinces }\end{array}$} & mean & 0.008 & 0.007 & 0.005 & 0.015 \\
\hline & $\mathrm{sd}$ & 0.030 & 0.033 & 0.032 & 0.019 \\
\hline \multirow{2}{*}{$\begin{array}{l}\text { D_never } \\
\text { provinces }\end{array}$} & mean & 0.007 & 0.006 & 0.007 & 0.011 \\
\hline & $\mathrm{sd}$ & 0.018 & 0.018 & 0.019 & 0.012 \\
\hline \multirow{2}{*}{$\begin{array}{l}\text { Alt_5084 } \\
\text { provinces }\end{array}$} & mean & 0.008 & 0.006 & 0.006 & 0.013 \\
\hline & sd & 0.023 & 0.022 & 0.027 & 0.013 \\
\hline \multirow{2}{*}{$\begin{array}{l}\text { Alt_5350 } \\
\text { provinces }\end{array}$} & mean & 0.007 & 0.006 & 0.006 & 0.012 \\
\hline & sd & 0.019 & 0.018 & 0.022 & 0.011 \\
\hline
\end{tabular}


Table 6: Summary statistics for real wage growth

\begin{tabular}{|c|c|c|c|c|c|}
\hline & & $\begin{array}{c}\text { Full Period } \\
\text { (April 2002- } \\
\text { December 2005) }\end{array}$ & $\begin{array}{c}\text { Period 0 } \\
\text { (April 2002- } \\
\text { December 2003) }\end{array}$ & $\begin{array}{c}\text { Period } 1 \\
\text { (January 2004- } \\
\text { April 2005) }\end{array}$ & $\begin{array}{c}\text { Period } 2 \\
\text { (May 2005 } \\
\text { December 2005) }\end{array}$ \\
\hline \multirow{2}{*}{$\begin{array}{l}\text { All } \\
\text { provinces }\end{array}$} & mean & 0.003 & 0.004 & 0.003 & 0.000 \\
\hline & $\mathrm{sd}$ & 0.104 & 0.115 & 0.109 & 0.050 \\
\hline \multirow{2}{*}{$\begin{array}{l}D \_5084 \\
\text { provinces }\end{array}$} & mean & 0.004 & 0.008 & 0.000 & -0.001 \\
\hline & sd & 0.071 & 0.084 & 0.066 & 0.037 \\
\hline \multirow{2}{*}{$\begin{array}{l}D \_5350 \\
\text { provinces }\end{array}$} & mean & 0.007 & 0.012 & 0.003 & -0.001 \\
\hline & sd & 0.125 & 0.171 & 0.073 & 0.048 \\
\hline \multirow{2}{*}{$\begin{array}{l}\text { D_never } \\
\text { provinces }\end{array}$} & mean & 0.005 & 0.006 & 0.006 & 0.001 \\
\hline & $\mathrm{sd}$ & 0.108 & 0.090 & 0.146 & 0.041 \\
\hline \multirow{2}{*}{$\begin{array}{l}\text { Alt_5084 } \\
\text { provinces }\end{array}$} & mean & 0.004 & 0.006 & 0.002 & 0.000 \\
\hline & $\mathrm{sd}$ & 0.070 & 0.072 & 0.077 & 0.046 \\
\hline \multirow{2}{*}{$\begin{array}{l}\text { Alt_5350 } \\
\text { provinces }\end{array}$} & mean & 0.004 & 0.008 & 0.003 & -0.001 \\
\hline & sd & 0.090 & 0.113 & 0.076 & 0.033 \\
\hline
\end{tabular}




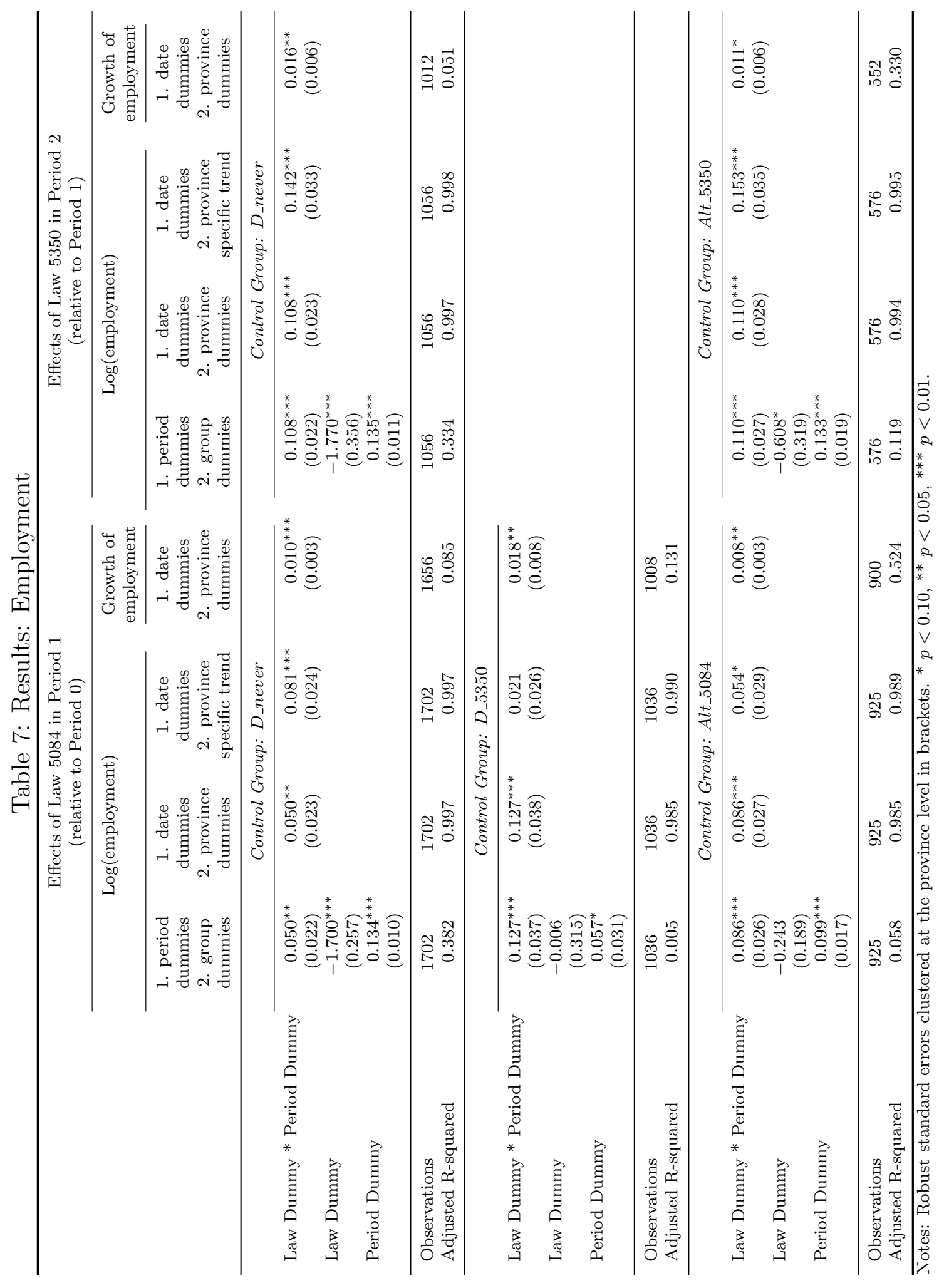




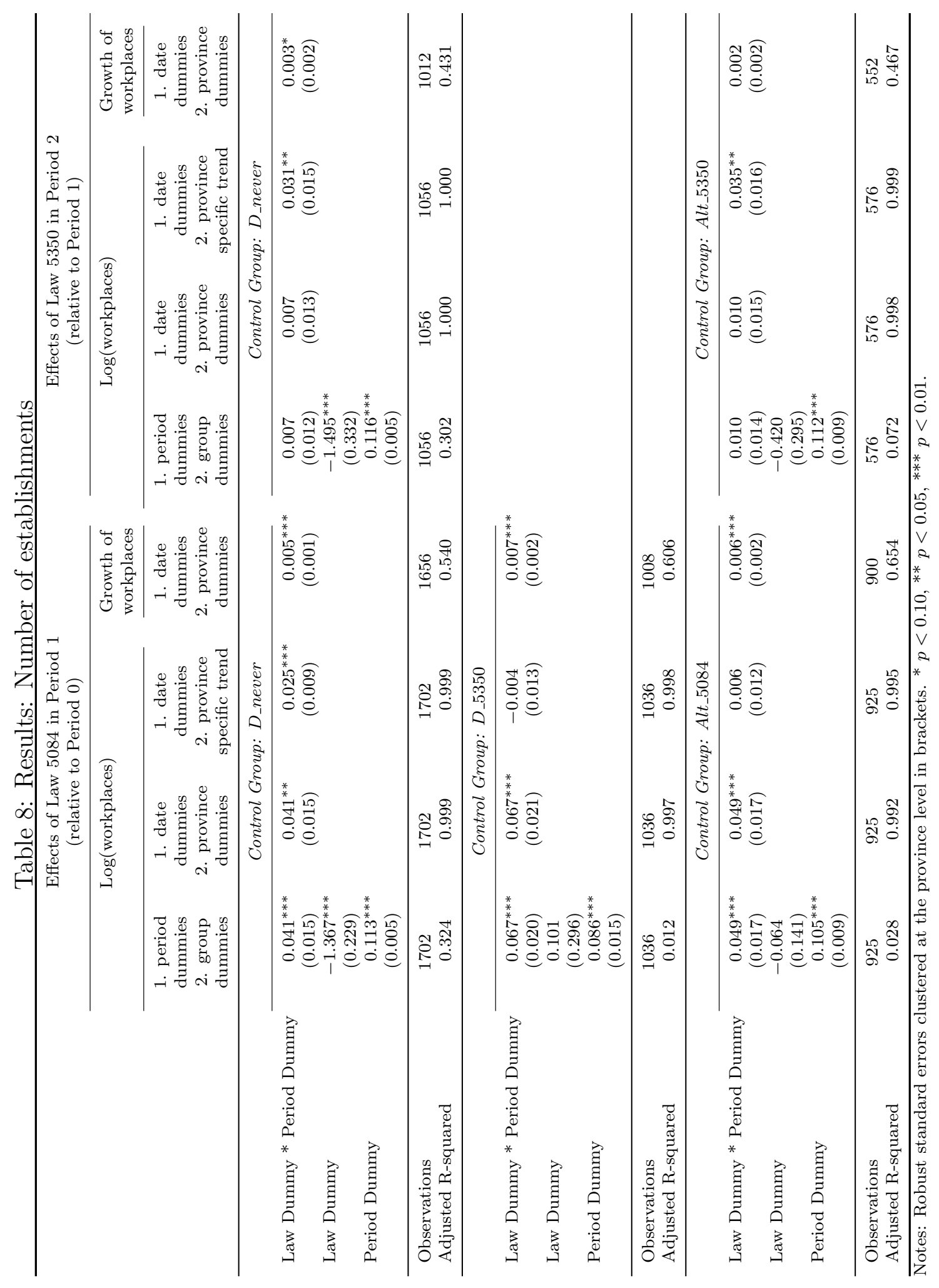




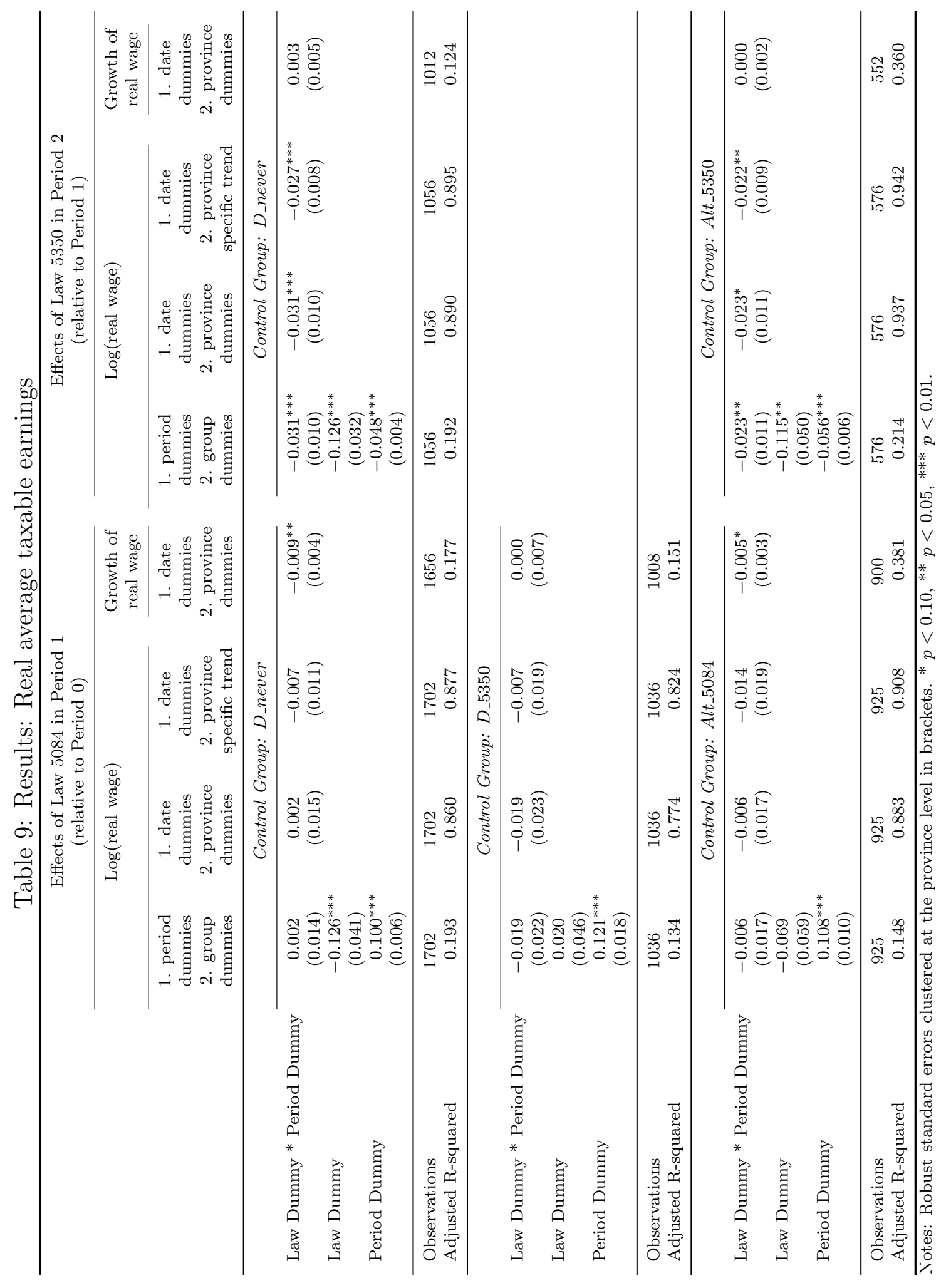


Table 10: Comparison of minimum wage to real average taxable earnings

\begin{tabular}{lcccccc}
\hline Date & $\begin{array}{c}\text { D_5084 } \\
\text { provinces }\end{array}$ & $\begin{array}{c}\text { D_5350 } \\
\text { provinces }\end{array}$ & $\begin{array}{c}\text { D_never } \\
\text { provinces }\end{array}$ & $\begin{array}{c}\text { Alt_5084 } \\
\text { provinces }\end{array}$ & $\begin{array}{c}\text { Alt_5350 } \\
\text { provinces }\end{array}$ & $\begin{array}{c}\text { Minimum } \\
\text { wage }\end{array}$ \\
\hline April 2002-June 2002 & 324.26 & 308.80 & 442.53 & 378.68 & 418.05 & 222.00 \\
July 2002-December 2002 & 357.89 & 326.88 & 461.04 & 404.44 & 416.97 & 250.88 \\
January 2003-December 2003 & 440.56 & 427.64 & 558.90 & 483.24 & 496.88 & 306.00 \\
January 2004-June 2004 & 565.37 & 551.96 & 694.48 & 616.49 & 629.44 & 423.00 \\
July 2004-December 2004 & 506.01 & 499.11 & 663.55 & 572.19 & 589.59 & 444.15 \\
January 2005-December 2005 & 542.84 & 540.57 & 719.09 & 609.93 & 633.97 & 488.70 \\
\hline
\end{tabular}




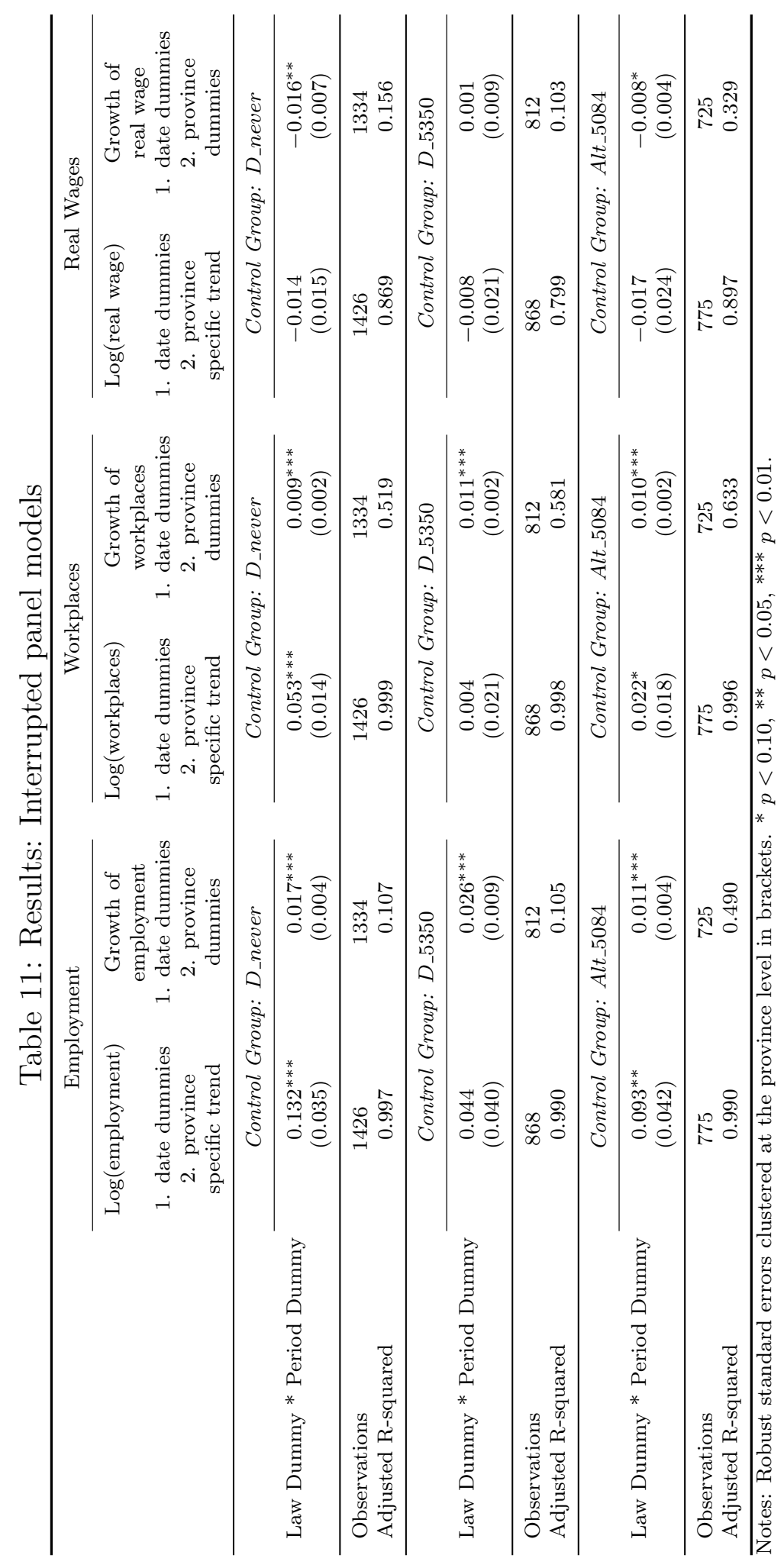


Table 12: Consumption of electricity in treated and control provinces

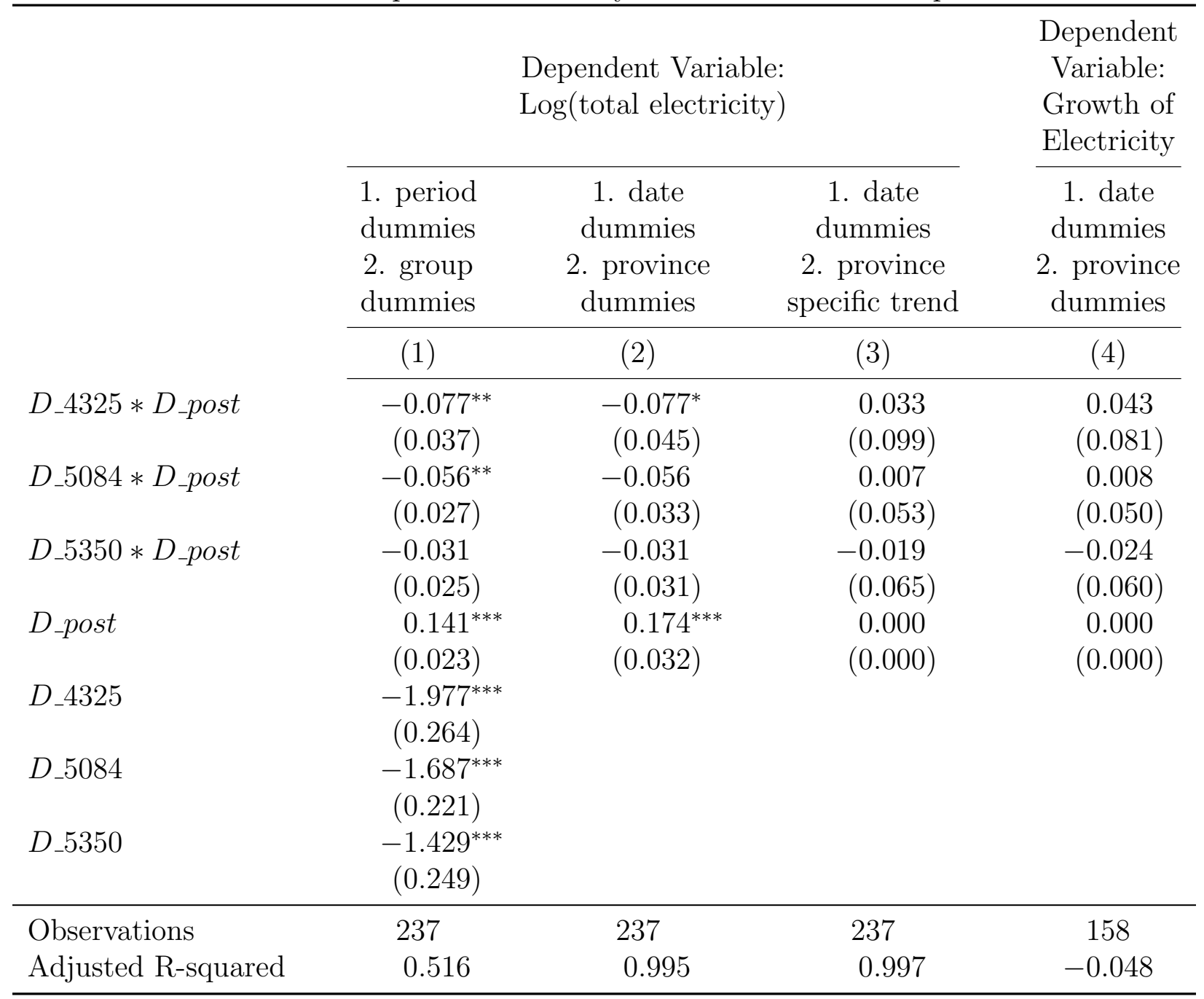

Notes: Robust standard errors in parentheses. ${ }^{* * *} p<0.01,{ }^{* *} p<0.05,{ }^{*} p<0.1$. 


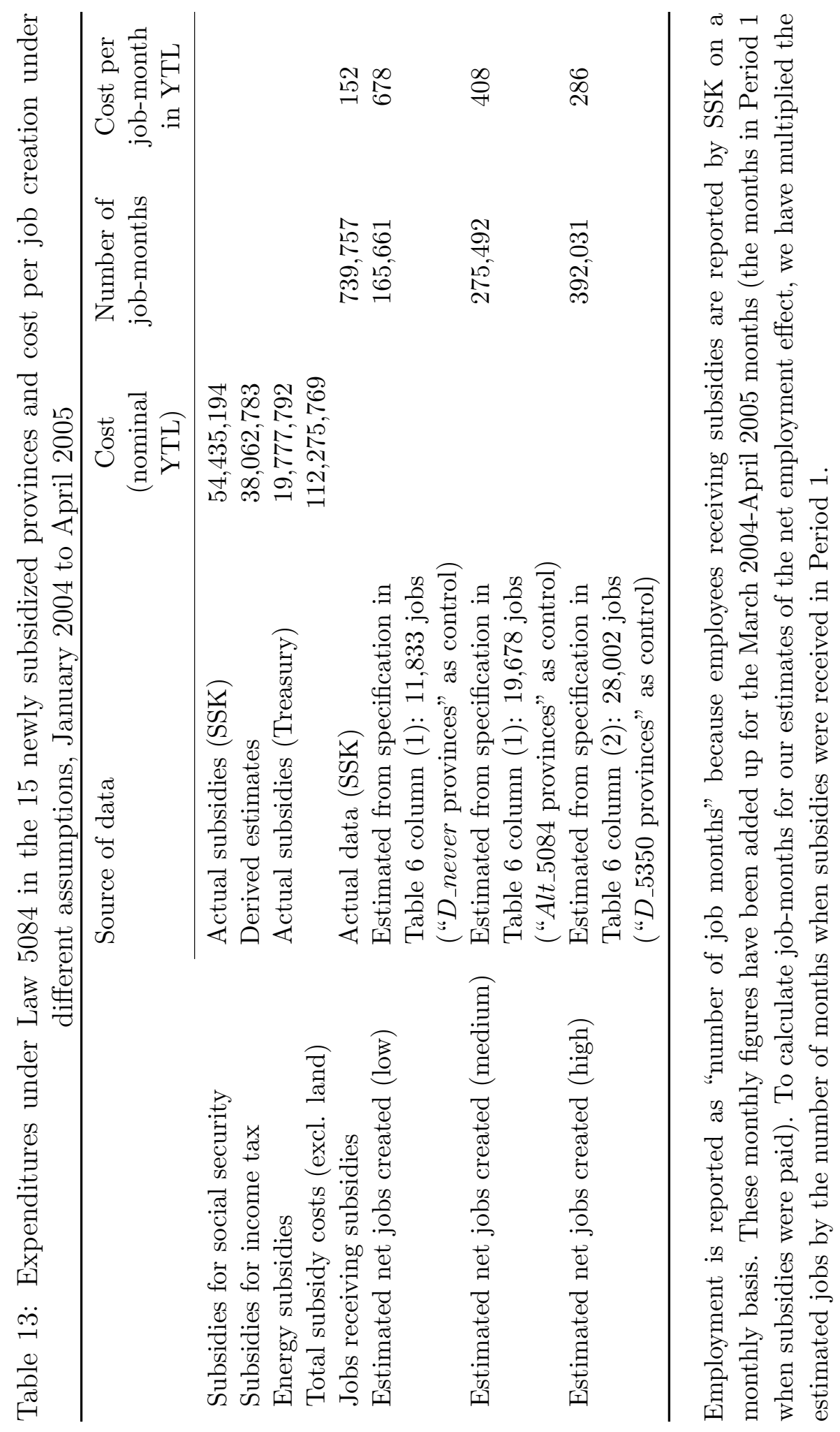




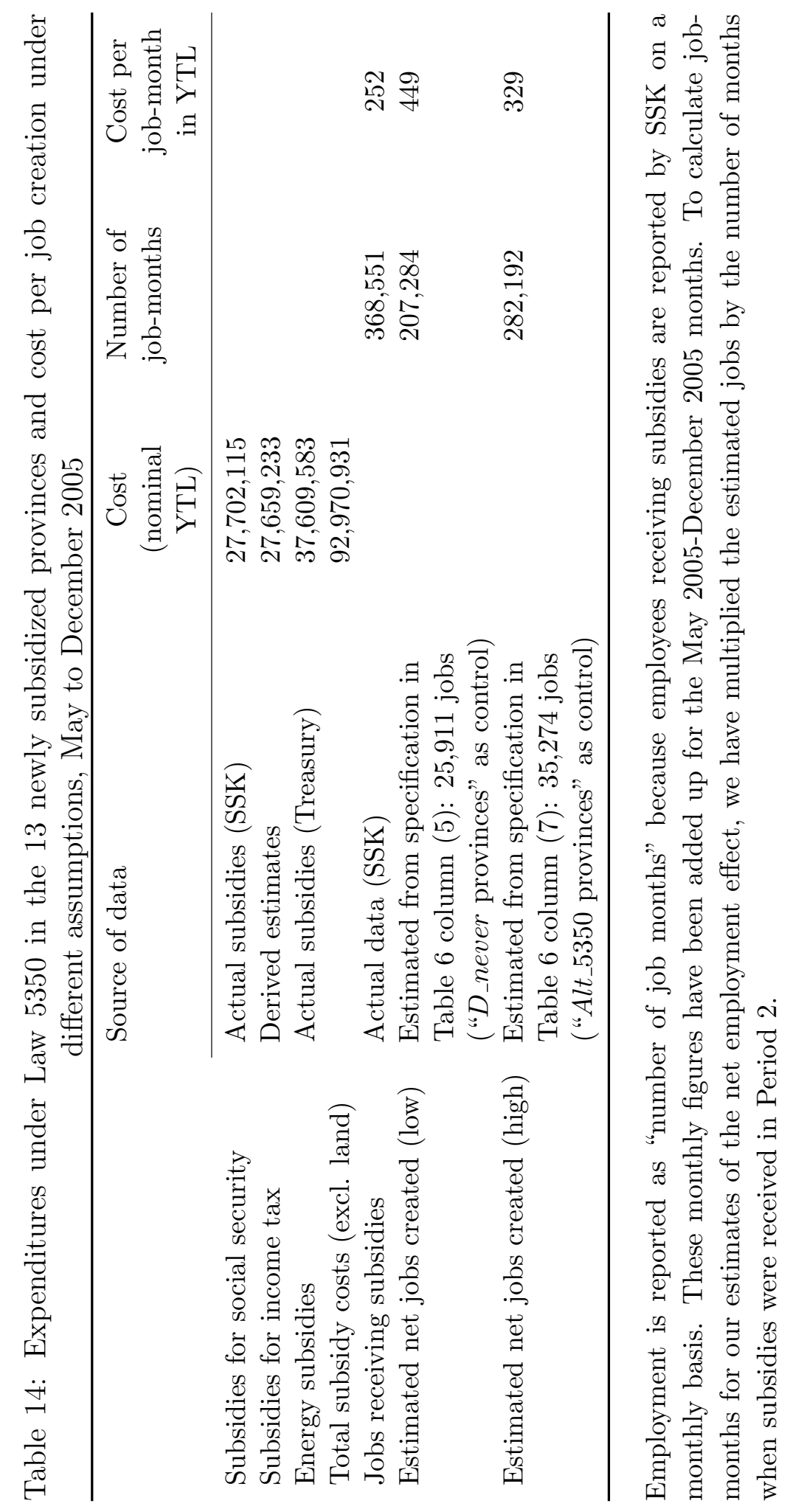

